\title{
An aspartate residue in the external vestibule of GLYT2 (glycine transporter 2) controls cation access and transport coupling
}

\author{
Gonzalo PÉREZ-SILES* $\dagger$, Enrique NÚÑEZ ${ }^{\star} \dagger$, Antonio MORREALE*, Esperanza JIMÉNEZ* $\dagger$, Alejandra LEO-MACÍAS*, \\ Guillermo PITA*, Francesca CHERUBINO $\S \|$, Rachele SANGALETTI§, Elena BOSSI§, Ángel R. ORTÍZ*1, \\ Carmen ARAGÓN ${ }^{*} \dagger+$ and Beatriz LÓPEZ-CORCUERA* $+\ddagger^{2}$ \\ *Departamento de Biología Molecular, Centro de Biología Molecular 'Severo Ochoa' (CSIC-UAM), Universidad Autónoma de Madrid, 28049 Madrid, Spain, †Centro de Investigación \\ Biomédica en Red de Enfermedades Raras (CIBERER), ISCIII, 28029 Madrid, Spain, †IDIPAZ-Hospital Universitario La Paz, Universidad Autónoma de Madrid, 28049 Madrid, Spain, \\ $\S$ Laboratory of Cellular and Molecular Physiology, Department of Structural and Functional Biology and Centre for Neuroscience, University of Insubria, 21100 Varese, Italy, and \\ „|Fondazione Maugeri IRCCS, Via Roncaccio 16, 21049 Tradate (VA), Italy
}

\begin{abstract}
Synaptic glycine levels are controlled by GLYTs (glycine transporters). GLYT1 is the main regulator of synaptic glycine concentrations and catalyses $\mathrm{Na}^{+}-\mathrm{Cl}^{-}$-glycine co-transport with a 2:1:1 stoichiometry. In contrast, neuronal GLYT2 supplies glycine to the presynaptic terminal with a $3: 1: 1$ stoichiometry. We subjected homology models of GLYT1 and GLYT2 to molecular dynamics simulations in the presence of $\mathrm{Na}^{+}$. Using molecular interaction potential maps and in silico mutagenesis, we identified a conserved region in the GLYT2 external vestibule likely to be involved in $\mathrm{Na}^{+}$interactions. Replacement of $\mathrm{Asp}^{471}$ in this region reduced $\mathrm{Na}^{+}$affinity and $\mathrm{Na}^{+}$co-operativity of transport, an effect not produced in the homologous position $\left(\mathrm{Asp}^{295}\right)$ in GLYT1. Unlike the GLYT1-Asp ${ }^{295}$ mutation, this $\mathrm{Asp}^{471}$ mutant increased sodium leakage and non-stoichiometric uncoupled ion movements through GLYT2, as determined by
\end{abstract}

simultaneously measuring current and $\left[{ }^{3} \mathrm{H}\right]$ glycine accumulation. The homologous $\mathrm{Asp}^{471}$ and $\mathrm{Asp}^{295}$ positions exhibited distinct cation-sensitive external accessibility, and they were involved in $\mathrm{Na}^{+}$and $\mathrm{Li}^{+}$-induced conformational changes. Although these two cations had opposite effects on GLYT1, they had comparable effects on accessibility in GLYT2, explaining the inhibitory and stimulatory responses to lithium exhibited by the two transporters. On the basis of these findings, we propose a role for $\mathrm{Asp}^{471}$ in controlling cation access to GLYT2 $\mathrm{Na}^{+}$sites, ion coupling during transport and the subsequent conformational changes.

Key words: glycine, glycine transporter (GLYT), lithium, neurotransmitter-sodium symporter, residue accessibility, sodium coupling.

\section{INTRODUCTION}

Glycine is the main inhibitory neurotransmitter in the caudal regions of the central nervous system and it exerts a positive modulation of excitatory transmission acting as a co-agonist of glutamate on NMDA ( $N$-methyl-D-aspartate) receptors [1]. Synaptic glycine is cleared by the $\mathrm{Na}^{+}$-driven $\mathrm{Cl}^{-}$-dependent high-affinity plasma membrane transporters GLYT (glycine transporter) 1 and GLYT2. GLYT1 is associated with both the glycinergic and glutamatergic pathways, and it is the main regulator of synaptic glycine levels [2]. In contrast, GLYT2 is located exclusively in glycinergic neurons and it supplies glycine to the nerve terminal, providing the substrate to refill synaptic vesicles via the low-affinity VIAAT (vesicular inhibitory amino acid transporter) [1]. The distinct physiological roles of the two glycine transporters are sustained by the higher sodium coupling required for glycine transport via GLYT2 (three $\mathrm{Na}^{+}$), as compared with GLYT1 (two $\mathrm{Na}^{+}$) [3,4]. Moreover, the two transporters differ notably in the transient $\mathrm{Na}^{+}$-dependent events that occur in the absence of substrate (pre-steady-state kinetics), thought to represent the initial stages of the transport cycle [4-6].

Gene-deletion studies demonstrated that whereas glycinergic inhibition is enhanced by suppressing the GLYT1 gene, it is attenuated by GLYT2 gene loss. Moreover, mutations in the
GLYT2 gene cause hyperekplexia in humans and congenital muscular dystonia type 2 in calves [7]. These findings suggest that selective modulation of GLYTs may improve defects in glycinergic neurotransmission [2,8,9]. In addition, GLYT1 inhibitors may improve cognitive deficits in schizophrenia by augmenting the glycine levels around NMDA receptors [9]. Accordingly, there is significant interest in developing specific GLYT1 and GLYT2 pharmacology.

Glycine transporters belong to the NSS (neurotransmittersodium symporter)/SLC (solute carrier) 6 family, together with GABA ( $\gamma$-aminobutyric acid) and monoamine transporters [10]. The three-dimensional structure of these transporters has been revealed by homology with a prokaryotic homologue, LeuT $_{\mathrm{Aa}}$ (leucine transporter from Aquifex aeolicus), the crystal structure of which was resolved at $1.65 \AA(1 \AA=0.1 \mathrm{~nm})$ (PDB code $2 \mathrm{~A} 65)$, providing a model for the eukaryotic transporters [11]. This structure revealed a novel protein fold and provided a clear view of the substrate-binding site and two $\mathrm{Na}^{+}$-binding sites ( $\mathrm{Na} 1$ and $\mathrm{Na} 2$ ). The carboxy group of the substrate directly contacts the $\mathrm{Na}^{+}$ion at the $\mathrm{Na}$ l site, providing a convincing explanation for the ion-substrate coupling during co-transport. Moreover, in eukaryotic transporters, a $\mathrm{Cl}^{-}$-binding site was identified in close proximity to the Na1 site [12-14]. The residues forming the external and cytoplasmic gates have been identified, and the

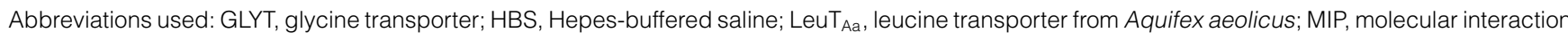
potential; MTS, methanethiosulfonate; MTSEA, 2-aminoethyl methanethiosulfonate; MTSES, (2-sulfonatoethyl) MTS; MTSET, [2-(trimethylammonium)ethyl] MTS bromide; NMDA, N-methyl-D-aspartate; NSS, neurotransmitter-sodium symporter; SLC, solute carrier; sulfo-NHS-SS-biotin, sulfosuccinimidyl-2(biotinamido)ethyl-1,3-dithiopropionate; TM, transmembrane region; TMA, tetramethylammonium; wt, wild-type.

Deceased.

2 To whom correspondence should be addressed (email blopez@cbm.uam.es) 
overall structure has provided a robust framework to explain the alternating access transport mechanism [15,16].

The LeuT $\mathrm{T}_{\mathrm{Aa}}$ model has also proved useful to analyse GLYT structure and function. Missense mutations affecting residues around the proposed glycine-binding site (W482R) and the Na1 site (N509S) inactivate GLYT2, and they cause hyperekplexia in humans [7]. Furthermore, a serine residue in the GLYT2 substrate site prevents its interaction with the bulkier sarcosine ( $N$-methylglycine), whereas the smaller glycine residue at this position in GLYT1 (Gly ${ }^{305}$, equivalent to $\mathrm{Ser}^{481}$ in GLYT2) enables it to use sarcosine as a substrate [17]. We recently demonstrated that the co-ordinating residues in the $\mathrm{Na} 1$ and $\mathrm{Na} 2$ sites are conserved in GLYTs [18], although the location of the third $\mathrm{Na}^{+}$site in GLYT2 is unknown. Using homology modelling and molecular dynamics simulations of GLYTs in the presence of $\mathrm{Na}^{+}$, we identified $\mathrm{Asp}^{471}$ [in TM6 (transmembrane region 6)], within a conserved region in the GLYT2 external vestibule, as a residue that was likely to interact with $\mathrm{Na}^{+}$. Mutations of $\mathrm{Asp}^{471}$ were analysed biochemically and electrophysiologically, revealing differential properties to the homologous GLYT1 position. Moreover, $\mathrm{Na}^{+}-$ affinity, $\mathrm{Na}^{+}$-co-operativity and $\mathrm{Na}^{+}$-glycine coupling during cotransport were altered in $\mathrm{Asp}^{471}$ mutants. Target cysteine residues in GLYT2 and GLYT1 homologous positions exhibited sodium and lithium-dependent accessibility and they mediated cationinduced conformational changes, which paralleled the effects of lithium on glycine transport [18]. Taken together, our findings support a role for $\mathrm{Asp}^{471}$ in controlling cation access to GLYT2 $\mathrm{Na}^{+}$sites, and in subsequent cation-substrate coupling.

\section{EXPERIMENTAL}

\section{Computational methods}

The crystallized leucine transporter from the bacterium $A$. aeolicus (LeuT $_{\mathrm{Aa}}$; PDB code 2A65) was used as the initial template [11]. To obtain the best possible alignment, we built a HMM (hidden Markov model) [19] with remote homologues found using PSI-BLAST [20]. Initial models for GLYT1 and GLYT2 with the bound substrate (glycine) were obtained using MODELLER [18,21]. As the LeuT $\mathrm{Aa}_{\mathrm{Aa}}$ sequence was shorter than those of GLYT1 and GLYT2, we used the ModLoop module from the MODELLER program, which generates different models for each loop. The lowest-energy model was selected in each case. Some additional molecular dynamics simulation steps were added, whereby the entire system was constrained and only the loops were allowed to move in order to prevent possible steric clashes during the loop generation step. Potential $\mathrm{Na}^{+}$-binding areas in the GLYTs were analysed in the models through the molecular dynamics trajectories and MIP (molecular interaction potential) maps. Simulations were prepared with the VMD molecular visualization program [22] and simulated with the NAMD 2.6 program [23], using the CHARMM force field. The GLYT1 homology model was immersed in a rectangular box of POPC (1-palmitoyl-2-oleoyl phosphatidylcholine) molecules and solvated with explicit water molecules on both sides of the membrane (12 $\AA$ layers). To simulate physiological conditions, $\mathrm{Na}^{+}$and $\mathrm{Cl}^{-}$ions were added at a concentration of $150 \mathrm{mM}$ $\mathrm{NaCl}$, and they were guided by electrostatic potential calculations (APBS program [24]). Next, a three-step protocol was used to equilibrate the protein in its environment. This consisted of a molecular mechanics minimization with initially fixed and then constrained backbones, followed by a gradual temperature increase up to $310 \mathrm{~K}$ and a final equilibration step at constant temperature $(310 \mathrm{~K})$ in which the constraints were gradually released. The total equilibration took $4 \mathrm{~ns}$. Next, GLYT1 was replaced with GLYT2 and both systems were again minimized, heated, equilibrated and finally simulated for an additional $0.5 \mathrm{~ns}$ (GLYT2) or $1.0 \mathrm{~ns}$ (GLYT1). The structures from this period were sampled for structural and energetic analyses at regular intervals (up to 35), MIPs [van der Waals (LennardJones 12-6) and electrostatics (linear Poisson equation)] for $\mathrm{Na}^{+}$ions were calculated for each of the structures and the Boltzmann average was determined. The mutants were built using the Mutator plugin (version 1.0) implemented in VMD. For each new structure generated, 20000 steps of molecular mechanics energy minimization were performed with the same force field as described above, and MIPS calculations were performed using these optimized geometries. To locate the position of the minimum value corresponding to the GLYT2 external vestibule, the 5000 MIP points with lowest energy were saved and grouped into five clusters using the original k-means algorithm [25], guided by the Euclidean distance implemented in the Cluster 3.02 program. A representative point (the minimal MIPs shown in Figure 1) was chosen on the basis of the average co-ordinates and energies for all of the points within the same cluster [26].

\section{Generation and expression of GLYT mutants}

Substitution mutants were generated by site-directed mutagenesis with the QuikChange ${ }^{\circledR}$ site-directed mutagenesis kit (Stratagene), using rat GLYT2 [27] and GLYT1 [28] (GenBank ${ }^{\circledR}$ accession numbers L21672 and M88595 respectively) in pcDNA3 as templates. Two independent Escherichia coli colonies carrying the mutant plasmids were characterized by sequencing and transport activity. The proteins were transiently expressed in COS7 cells as described previously [29] using Lipofectamine ${ }^{\mathrm{TM}}$ Plus (Invitrogen) or Neofectin ${ }^{\mathrm{TM}}$ (Mid Atlantic Biolabs). For mutants with reduced membrane expression, the total DNA was increased to enhance glycine transport. Cells were incubated for $48 \mathrm{~h}$ at $37^{\circ} \mathrm{C}$ prior to use.

\section{Glycine transport assay}

Transport assays in COS7 cells were performed at $37^{\circ} \mathrm{C}$ in $0.25 \mathrm{ml}$ of HBS [Hepes-buffered saline: $150 \mathrm{mM} \mathrm{NaCl}, 10 \mathrm{mM}$ Hepes/Tris (pH 7.4), $1 \mathrm{mM} \mathrm{CaCl} 2,5 \mathrm{mM} \mathrm{KCl}, 1 \mathrm{mM} \mathrm{MgSO}$ and $10 \mathrm{mM}$ glucose] containing $2 \mu \mathrm{Ci} / \mathrm{ml}{ }^{3} \mathrm{H}$-labelled glycine (1.6 TBq/mmol; PerkinElmer) and were isotopically diluted to a final glycine concentration of $10 \mu \mathrm{M}$ as described previously [29], unless specified otherwise. Reactions were terminated after $10 \mathrm{~min}$ by aspiration followed by a brief rinse with HBS. Transport was measured by subtracting the glycine accumulated in mocktransfected COS7 cells from that of the transporter-transfected cells and normalized to the protein concentration. In $\mathrm{Na}^{+}$dependence experiments, $\mathrm{NaCl}$ was isotonically replaced by choline chloride, $\mathrm{LiCl}$ or a combination of both, as indicated in the Figure legends. Kinetic analyses were performed by varying the glycine concentration in the uptake medium from $10 \mu \mathrm{M}$ to $1000 \mu \mathrm{M}$.

\section{Oocyte expression}

The detailed experimental procedure can be found in [30]. The desired cDNA was linearized with an appropriate enzyme and cRNA synthesized and capped (Cap Analog and 200 units of T7 RNA polymerase; Promega). Xenopus laevis frogs were anaesthetized with MS222 (tricaine methanesulfonate, $0.10 \%$ ), their ovaries were removed and the animals were humanely killed. The experiments were carried out in accordance with institutional and national ethical guidelines. The oocytes were treated with $1 \mathrm{mg} / \mathrm{ml}$ collagenase (Type IA; Sigma) in $\mathrm{Ca}^{+}$-free ND96 for 
at least $1 \mathrm{~h}$ at $18^{\circ} \mathrm{C}$. Healthy oocytes (stages V and VI) were collected and injected with $12.5 \mathrm{ng}$ of cRNA in $50 \mathrm{nl}$ of water, using a manual microinjection system (Drummond). The oocytes were incubated at $18^{\circ} \mathrm{C}$ for 3-4 days in MBS (modified Barth's saline) solution before electrophysiological studies.

\section{Electrophysiology and data analysis}

A classic two-electrode voltage-clamp set up (GeneClamp, Axon Instruments; or Oocyte Clamp OC- 725B, Warner Instruments) was used to record membrane currents under voltage-controlled conditions at room temperature $\left(22^{\circ} \mathrm{C}\right)$. Reference electrodes were connected to the experimental oocyte chamber via agar bridges ( $3 \%$ agar in $3 \mathrm{M} \mathrm{KCl})$. Borosilicate electrodes, with a tip resistance of $0.5-2 \mathrm{M} \Omega$, were filled with $3 \mathrm{M} \mathrm{KCl}$. The holding potential $\left(\mathrm{V}_{\mathrm{h}}\right)$ was maintained at $-40 \mathrm{mV}$, unless otherwise stated. Voltage pulses to test potentials from -140 to $+40 \mathrm{mV}$ in $20 \mathrm{mV}$ increments were applied, and four pulses were averaged at each potential to improve the signal-to-noise ratio. Signals were filtered at $1 \mathrm{kHz}$ and sampled at $2 \mathrm{kHz}$. Long-lasting recordings were filtered at $20 \mathrm{~Hz}$ and sampled at $50 \mathrm{~Hz}$. Data analysis was performed using Clampfit 8.2 (Axon Instruments). All figures were prepared with Origin 8.0 (Microcal Software). The external control solution for oocytes contained $98 \mathrm{mM} \mathrm{NaCl}, 1.8 \mathrm{mM}$ $\mathrm{CaCl}_{2}, 1 \mathrm{mM} \mathrm{MgCl}$ and $5 \mathrm{mM}$ Hepes-free acid. Where indicated, $\mathrm{NaCl}$ was replaced with equimolar TMA (tetramethylammonium) chloride. The $\mathrm{pH}$ was adjusted to 7.6 by adding $\mathrm{NaOH}$ or TMA hydroxide as appropriate.

\section{Simultaneous measurement of glycine uptake and glycine-induced currents}

The ion/substrate stoichiometry of GLYTs was determined by simultaneous measurement of glycine-induced inward currents and $\left[{ }^{3} \mathrm{H}\right]$ glycine influx under voltage-clamp conditions [31]. The membrane potential was clamped at $-40 \mathrm{mV}$ and after an initial baseline period in $98 \mathrm{mM} \mathrm{Na}^{+}$buffer, oocytes were superfused for 5 min with a buffer containing $100 \mu \mathrm{M}$ $\left[{ }^{3} \mathrm{H}\right]$ glycine (final specific activity of $1.1 \mathrm{MBq} \cdot \mathrm{mmol}^{-1}$ ). Oocytes were perfused with ice-cold buffer, removed from the chamber, washed and solubilized for liquid-scintillation counting. The total substrate-evoked inward charge was obtained from the time integral of the substrate-evoked current, converted into a molar equivalent using the Faraday constant, and was related to the amount of glycine uptake in the same oocyte. Non-specific glycine uptake was determined using water-injected control oocytes analysed under the same conditions and this parameter was subtracted from the transport data from the cRNA-injected oocytes.

\section{Inhibition studies with the impermeant thiol reagents MTSET \{[2-(trimethylammonium)ethyl] MTS (methanethiosulfonate) bromide $\}$ and MTSES [(2-sulfonatoethyl) MTS]}

Before measuring transport, transfected COS7 cells grown on polylysine-covered 24-well plates were washed with $1 \mathrm{ml}$ of HBS and then pre-incubated with $300 \mu \mathrm{l}$ of medium containing the indicated concentrations of MTSET or MTSES (Toronto Research Chemicals) from a $100 \times$ stock solution in water (freshly prepared for each experiment). Following a $10 \mathrm{~min}$ pre-incubation, the medium was removed and the cells were washed once with $1 \mathrm{ml}$ of the same solution and at least twice with $1 \mathrm{ml}$ of HBS ( $\mathrm{NaCl}$ transport medium). All procedures were performed at $22^{\circ} \mathrm{C}$ unless indicated otherwise. After $5 \mathrm{~min}$ at $37^{\circ} \mathrm{C}$, the cells were assayed for $\left[{ }^{3} \mathrm{H}\right]$ glycine transport as described above. The transport detected was due to the activity of non-reactive transporters [5].

\section{Surface labelling with MTSEA (2-aminoethyl methanethiosulfonate)-biotin and sulfo-NHS-SS-biotin [sulfosuccinimidyl-2-(biotinamido)ethyl-1,3-dithiopropionate]}

Thiol-specific biotinylation and total surface biotinylation was performed with MTSEA-biotin (Toronto Research Chemicals) and sulfo-NHS-SS-biotin (Pierce) on transfected COS7 cells [29], using $0.5 \mathrm{mM}$ MTSEA-biotin and a $3 \mathrm{~h}$ incubation with streptavidin-agarose beads (Sigma). Proteins (reagent-reactive transporters) were eluted from the beads with Laemmli buffer [40 mM Tris/HCl (pH 6.8), $2 \%$ (w/v) SDS, $10 \%$ (v/v) glycerol, $0.1 \mathrm{M}$ DTT (dithiothreitol) and $0.01 \%$ Bromophenol Blue] for $10 \mathrm{~min}$ at $70^{\circ} \mathrm{C}$, and then analysed by Western blotting (SDS/7.5\% PAGE) with GLYT1- and GLYT2-specific antibodies $[32,33]$. Protein bands were visualized by ECL (enhanced chemiluminescence) and quantified on a GS-710 Calibrated Imaging Densitometer (Bio-Rad Laboratories) using Quantity One software and film exposures in the linear range. Calnexin immunoreactivity was used as a loading control and S.E.M. values were calculated from at least three separate experiments.

\section{Data analysis}

Non-linear regression fits of experimental transport data were achieved with Origin. Results are means \pm S.E.M. from experiments that were repeated at least three times with equivalent outcomes.

\section{RESULTS}

\section{Molecular dynamics simulations of GLYT homology models and characterization of selected mutants}

Using molecular dynamics simulations of GLYT1 and GLYT2 models based on their structural homology with LeuT $_{\mathrm{Aa}}$ [11], we identified a conserved region in the GLYT2 external vestibule likely to interact with $\mathrm{Na}^{+}$(Figures 1A-1D and Supplementary Figure S1 at http://www.BiochemJ.org/bj/442/bj4420323add. $\mathrm{htm})$. In silico substitutions and calculated MIP maps for $\mathrm{Na}^{+}$ ions predicted a decrease in the minimum MIP energy when residues shown in Figure 1(A) were replaced, which was most apparent for $\mathrm{Asp}^{471}, \mathrm{Asp}^{542}$ and $\mathrm{Asp}^{635}$ (Figure 1E). High MIP residues were mutated and the mutants expressed in COS7 cells (Figures 2A and 2B). Although the majority of mutants reached the plasma membrane [75-100\% of wt (wild-type) membrane expression; Figure 2A], only the most conservative substitution at each position yielded active transporters (Figure 2B). When active mutants were assayed for the sodium-dependence of glycine transport, wt phenotypes were observed (Figures 2C and 2D). An exception was Asp ${ }^{471}$. Mutation of this residue did not produce functional rescue, even after the most conservative substitution to glutamic acid, whereas its replacement by other amino acids generated weakly active transporters (Figure 2B and Table 1). Transport by $\mathrm{Asp}^{471}$ mutants did not reach saturation by sodium at physiological $\mathrm{NaCl}$ concentrations $(150 \mathrm{mM})$, and the apparent affinity and co-operativity for $\mathrm{Na}^{+}$were lower than the wt (Figure 2E and Table 1). In contrast, substitution mutants of the homologous aspartate residue in GLYT1 (Asp ${ }^{295}$ [34]) displayed sodium-dependence curves and kinetic parameters for 
A

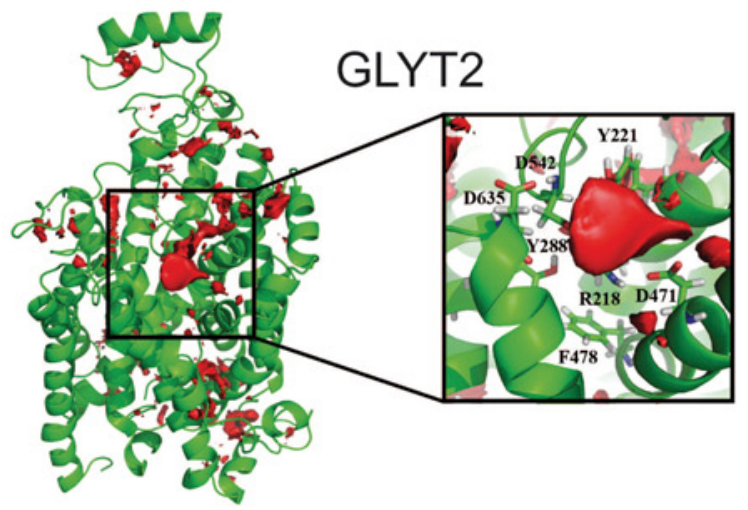

C GLYT2

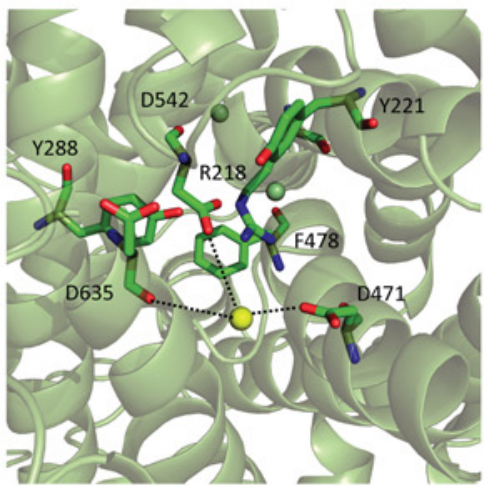

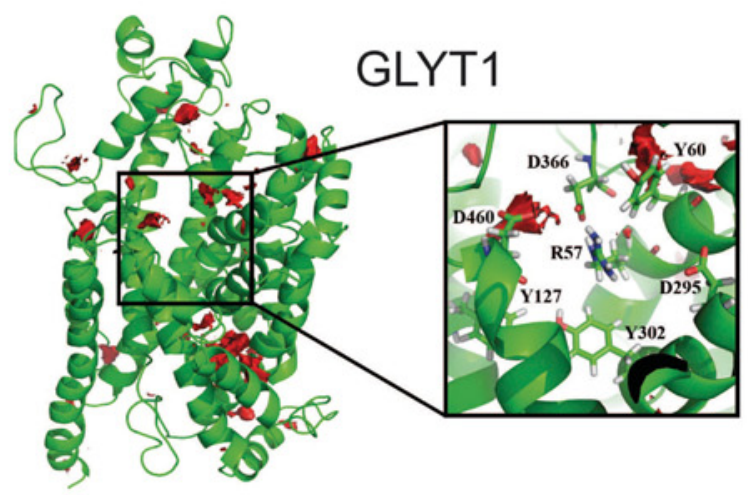

D GLYT1

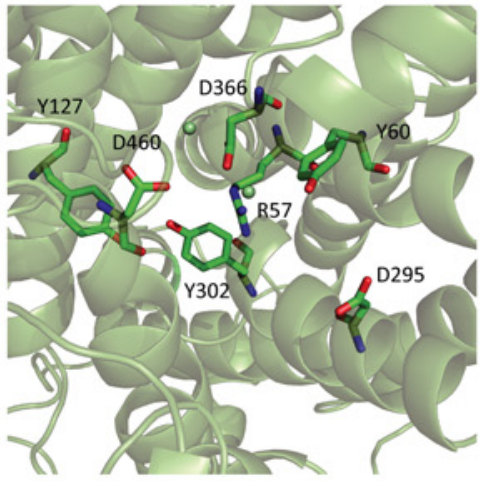

E

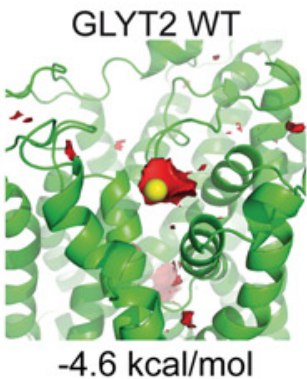

D635C

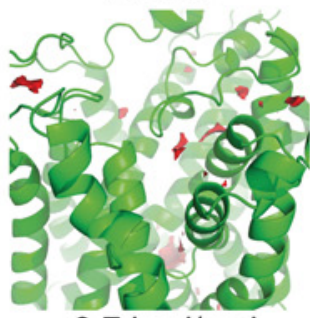

$-3.7 \mathrm{kcal} / \mathrm{mol}$

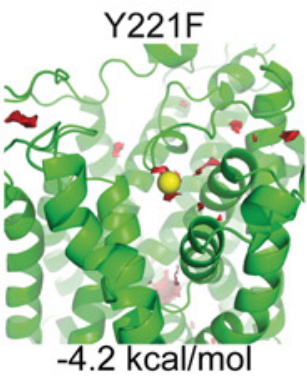

D542C

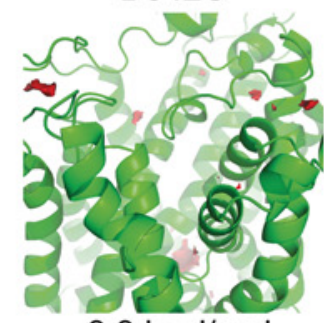

$-3.3 \mathrm{kcal} / \mathrm{mol}$
Y288C

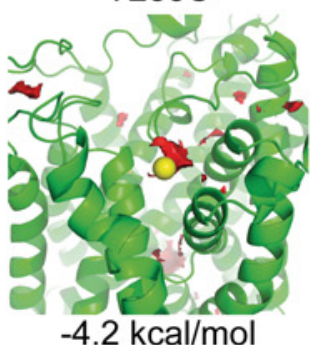

D471A

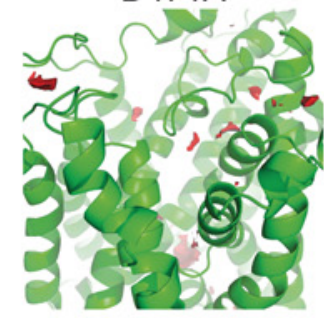

$-3.3 \mathrm{kcal} / \mathrm{mol}$

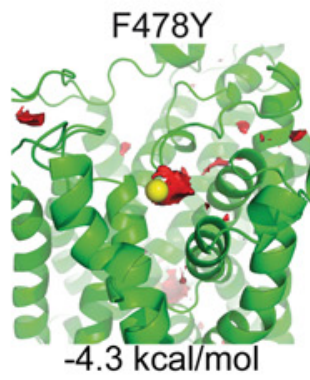

D471C

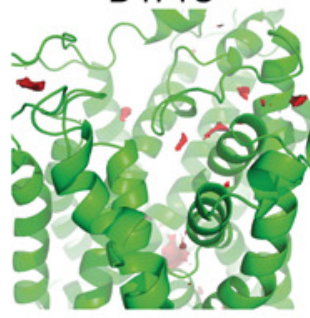

$-3.3 \mathrm{kcal} / \mathrm{mol}$

Figure 1 GLYT2 external vestibule contains residues with high MIPs for sodium 
A

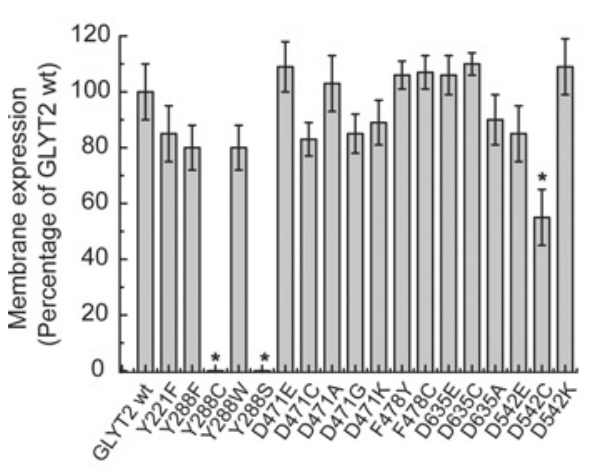

C

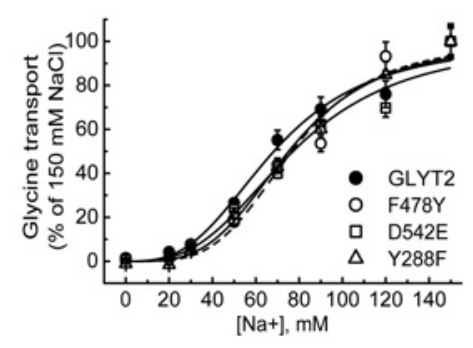

E

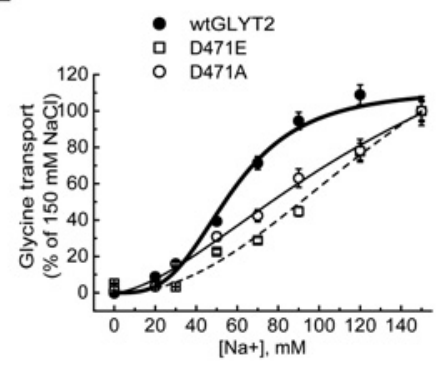

B

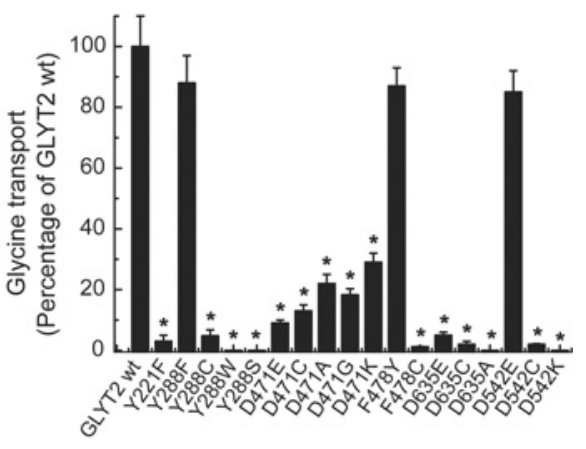

D

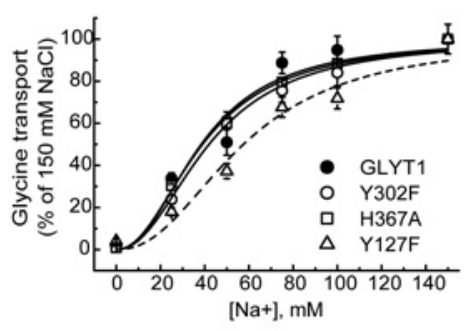

F

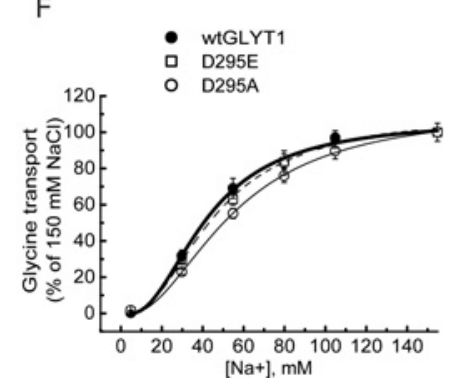

Figure 2 Mutagenesis and functional analysis of GLYT2 residues with high MIPs

COS7 cells expressing the wtGLYT2 or the indicated GLYT2 (A-C and E) or GLYT1 mutants (D and F) were subjected to NHS-SS-biotinylation and analysed by Western blotting $(\mathbf{A})$, or were assayed for glycine transport with $10 \mu \mathrm{M}$ glycine in $\mathrm{HBS}$ containing $150 \mathrm{mM} \mathrm{NaCl}(\mathbf{B})$ or the indicated $\mathrm{NaCl}$ concentration by isotonic substitution of $\mathrm{NaCl}$ with choline chloride $(\mathbf{C}-\mathbf{F})$. ${ }^{*} P<0.05$ with respect to wtGLYT2 (ANOVA with Dunnett's post-hoc test). (C) $100 \%$ glycine transport (nmol of glycine/mg of protein per $10 \mathrm{~min}$ ): GLYT2, 3.1 + 0.4. Mutants: Y288F, $90+8 \%$; F478Y, $92+9 \%$; D542E, $87 \pm 8 \%$ of wtGLYT2. (D) GLYT1, 5.2 \pm 0.6. Mutants: Y127F, $10 \pm 1 \% ; Y 302 F, 10 \pm 1 \% ; H 367 A, 81 \pm 7 \%$ of wtGLYT1. (E) $100 \%$ wtGLYT2 transport: $3.05 \pm 0.5$. Asp 471 mutants: D471A, $0.98 \pm 0.2 ; \mathrm{D} 471 \mathrm{E}, 0.47 \pm 0.1$. (F) $100 \%$ GLYT1 transport: $5.2 \pm 0.6$. Asp ${ }^{295}$ mutants: D295A, $0.93 \pm 0.1$; D295E, $4.53 \pm 0.4$. Experimental data were fitted to the Hill equation.

$\mathrm{Na}^{+}$similar to those of wtGLYT1 $\left(\mathrm{EC}_{50}\right.$ and Hill coefficient; Figure 2F and Table 1). Thus the sodium-dependence of glycine transport was affected distinctly by mutation of homologous GLYT aspartate residues, suggesting that the interaction between $\mathrm{Na}^{+}$ions and the transporter was selectively altered in GLYT2 [see functional features of $\mathrm{Asp}^{471}$ (GLYT2) and $\mathrm{Asp}^{295}$ (GLYT1) mutants in Table 1] expected, the decrease in the apparent affinity and co-operativity for $\mathrm{Na}^{+}$was accompanied by reductions in
$V_{\max }$ and increases in $K_{\mathrm{m}}$, revealing a crucial role of the aspartate in glycine transport.

\section{Electrophysiological characterization of Asp ${ }^{471}$ (GLYT2) and Asp 295 (GLYT1) mutants}

The electrophysiological parameters of transporters containing alanine substitutions of the homologous aspartate residues were

(A and B) Lateral view of the modelled GLYT2 (A) and GLYT1 (B) structures showing the isosurfaces corresponding to favourable interactions with Na ${ }^{+}$ions ( $-5 \mathrm{kcal} / \mathrm{mol}$, red). The region containing residues with high MIPs for Na ${ }^{+}$ions in GLYT2 is magnified to compare it with the equivalent area of GLYT1. (C and D) External view of the GLYT external vestibule showing the positions of Asp ${ }^{471}$ in GLYT2 (C) and Asp 295 in GLYT1 (D) relative to the Na1 and Na2 sites. Na ${ }^{+}$ions are represented as small green spheres. In (C), the location of the Na ${ }^{+}$ion corresponds to the minimum MIP found in the area (yellow sphere; see the Experimental section). The protein is shown in green and the main residues as sticks coloured by atom type (green, blue, and red for carbon, nitrogen and oxygen atoms respectively). Hydrogen atoms have been omitted for clarity. Broken black lines in (C) denote residues in close contact with $\mathrm{Na}^{+}$ions. (E) Representation of the MIP surface (in red and contoured at $-5 \mathrm{kcal} / \mathrm{mol}$ ) located at the external vestibule area of wtGLYT2 and different in silico mutants. The position of the minimum MIP found in this area is highlighted by a small yellow sphere. The GLYT2 structure is represented in green. The energy corresponding to each minimum MIP is also shown. 
Table 1 Kinetic parameters of glycine transport by Asp ${ }^{471}$ (GLYT2) and Asp ${ }^{295}$ (GLYT1) mutants

Experimental conditions were as in Figures 2(C)-2(F). Values are means \pm S.E.M. for experiments performed in triplicate at $10 \mu \mathrm{M}$ glycine and $150 \mathrm{mM} \mathrm{NaCl}$. > or $<$ indicates that transport was not saturated at the maximum concentration assayed. $\mathrm{NH}$, non-hyperbolic.

\begin{tabular}{|c|c|c|c|c|c|}
\hline & Transporter & $V_{\max }(\mathrm{nmol} / \mathrm{mg}$ per $10 \mathrm{~min})$ & $K_{\mathrm{m}}(\mu \mathrm{M})$ & $\mathrm{EC}_{50}(\mathrm{mM})\left(\mathrm{Na}^{+}\right)^{\star}$ & $h$ (Hill coefficient) $\left(\mathrm{Na}^{+}\right)^{*}$ \\
\hline \multirow[t]{2}{*}{ wt } & GLYT2 & $52 \pm 2.5$ & $143 \pm 25$ & $66 \pm 14$ & $2.8 \pm 0.2$ \\
\hline & GLYT1 & $93 \pm 8.7$ & $136 \pm 19$ & $71 \pm 8.2$ & $2.0 \pm 0.4$ \\
\hline \multirow{4}{*}{ D471 (GLYT2) } & $\mathrm{D} 471 \mathrm{~A}$ & $23 \pm 1.4$ & $200 \pm 34$ & $>150$ & $<2.0$ \\
\hline & D471C & $12 \overline{ \pm} 1.5$ & $194 \pm 16$ & $86 \pm 9.3$ & $2.0 \pm 0.4$ \\
\hline & $\mathrm{D} 471 \mathrm{G}$ & $\mathrm{NH}^{-}$ & $>10 \overline{0} 0$ & $>1 \overline{50}$ & $<2 . \overline{0}$ \\
\hline & D471K & $25 \pm 8.0$ & $572 \pm 45$ & $66 \pm 2.4$ & $2.0 \pm 0.3$ \\
\hline \multirow{3}{*}{ D295 (GLYT1) } & D295C & $15+1.2$ & $195+19$ & $88 \pm 10$ & $2.0+0.4$ \\
\hline & D295G & $20 \pm 2.8$ & $272 \pm 25$ & $95 \pm 9.2$ & $1.9 \pm 0.6$ \\
\hline & D295K & $25 \pm 3.3$ & $317 \pm 29$ & $80 \pm 6.8$ & $1.9 \pm 0.4$ \\
\hline
\end{tabular}

tested in Xenopus laevis oocytes. Currents induced by $1 \mathrm{mM}$ glycine at different sodium concentrations were recorded at $-40 \mathrm{mV}$ from four representative oocytes (Figure 3A, GLYT2, and Figure 3B, GLYT1). As reported previously [5], wtGLYT2 displayed leak currents, a constitutive transport-independent conductance that is only detected in the absence of substrate, calculated by subtracting the current measured in the presence of permeating ions from that measured in the presence of nonpermeating ions, in this case TMA. These currents were sodiumdependent and were larger in the D471A mutant than in wtGLYT2, and they were never visualized in GLYT1 (GLYT2 currents in the absence of glycine under a voltage-step protocol are shown in Figure 3C). The current from the GLYT2 mutant increased with negative voltage and increasing sodium concentration, and thus it was visibly larger than that of wtGLYT2 at the highest $\mathrm{Na}^{+}$ concentration used $(98 \mathrm{mM})$. This behaviour is compatible with increased sodium leakage of the GLYT2 mutant.

The mutation of the homologous aspartate residues had opposing effects in the two transporters in terms of the transportassociated currents (substrate-induced currents). GLYT2D471A transport currents were larger than in the wt (Figure 3A), whereas transport currents in the GLYT1 mutant were lower (approximately 60\%; Figure 3B) than in the wt. These opposing effects were clearly detected after application of the aforementioned voltage-step protocol and plotting the net glycine-elicited currents $\left(I_{\mathrm{Tr}_{-} \mathrm{Gly}}=I_{\mathrm{Na}_{\text {G }} \mathrm{Gly}}-I_{\mathrm{Na}}\right)$ against the voltage (Figure 4). GLYT2 mutant currents increased with negative voltage and increasing sodium concentration (Figure 4A), and trended to display a current reversal, whereas no such behaviour was evident with the GLYT1 mutant currents (Figure 4B).

Although the small transport currents observed in GLYT1 mutants were consistent with the decreased $\left[{ }^{3} \mathrm{H}\right]$ glycine transport displayed by these mutants in COS7 cells (Table 1 and Figure 2B), the large currents detected in the D471A mutant were unexpected. Thus we analysed radioactive glycine flux in oocytes, confirming that both GLYT2 and GLYT1 mutants showed similar levels of $\left[{ }^{3} \mathrm{H}\right]$ glycine transport as those of the wt controls (Figures $5 \mathrm{~A}$ and $5 B$ ). The discrepancy observed between currents and radioactive substrate transport in the GLYT2 mutant suggested the presence of a current in excess of that associated with the stoichiometric charge translocation [35], such that the mutation increased nonstoichiometric or uncoupled ion movements mediated by GLYT2. To confirm this hypothesis, we determined the charge/glycine flux ratios by simultaneously measuring current and $\left[{ }^{3} \mathrm{H}\right]$ glycine accumulation in the same oocyte (Figure 5C). GLYT2 moves two positive charges per transported glycine molecule [4], and our measurements revealed a value of $2.3 \pm 0.7(n=4)$, increasing to $11.0 \pm 1.5(n=5)$ in the D471A mutant, significantly greater than the wtGLYT2 value. In contrast, the charge/flux coupling ratios for wtGLYT1 and the D295A mutant were $1.2 \pm 0.3$ $(n=4)$ and $1.7 \pm 0.2(n=4)$ respectively. These data confirm the distinct consequences of aspartate mutation in the two glycine transporters, demonstrating the disrupted coupling between $\mathrm{Na}^{+}$ and glycine transmembrane flux induced by the D471A mutation in GLYT2.

\section{Asp ${ }^{471}$ mutation (GLYT2) alters the transporter response to lithium ions}

We previously reported that wtGLYTs respond differentially to the presence of lithium, which stimulates $\mathrm{Na}^{+}$-driven transport via GLYT2, but inhibits it via GLYT1 [18,36,37]. We investigated whether the effect of lithium on the GLYTs was altered by mutation of the homologous aspartate residues. The physiological $\mathrm{NaCl}$ concentration of $150 \mathrm{mM}$ was reduced to $50 \mathrm{mM}$ upon addition of $100 \mathrm{mM}$ choline chloride or $\mathrm{LiCl}$ (Figure 6A). As expected, replacement of $\mathrm{Na}^{+}$with choline (which does not interact with the transporters) reduced glycine transport, slightly more affecting transport to GLYT2 and D471A, which are more dependent on sodium (remaining transport activity $71-74 \%$ at $150 \mathrm{mM} \mathrm{NaCl}$, closed bars), than GLYT1 transporters (86-87\%, closed bars). In contrast, partial substitution of sodium by lithium revealed the different responses of wt transporters, where GLYT2 was stimulated, whereas GLYT1 was inhibited as compared with choline substitution. Interestingly, although the GLYT1D295A mutant displayed a wt-like response, being inhibited by lithium, the GLYT2D471A mutant was not stimulated by lithium, in direct contrast with its corresponding wt. This change in the lithium response of the GLYT2D471A mutant was more evident when the $V_{\max }$ of glycine transport was measured in the two previous ionic conditions (Figures 6B and 6C). All GLYT1 and GLYT2 aspartate mutants exhibited similar responses to their corresponding wt controls, except for the GLYT2D471A mutant (Figure 6B). The absence of an altered response to lithium in the GLYT2D471E mutant suggests that this change is due to $\mathrm{Asp}^{471}$ neutralization. Given that the differential lithium responses are mediated by lithium binding to the $\mathrm{Na} 2$ sites of GLYTs [18], our results 
A

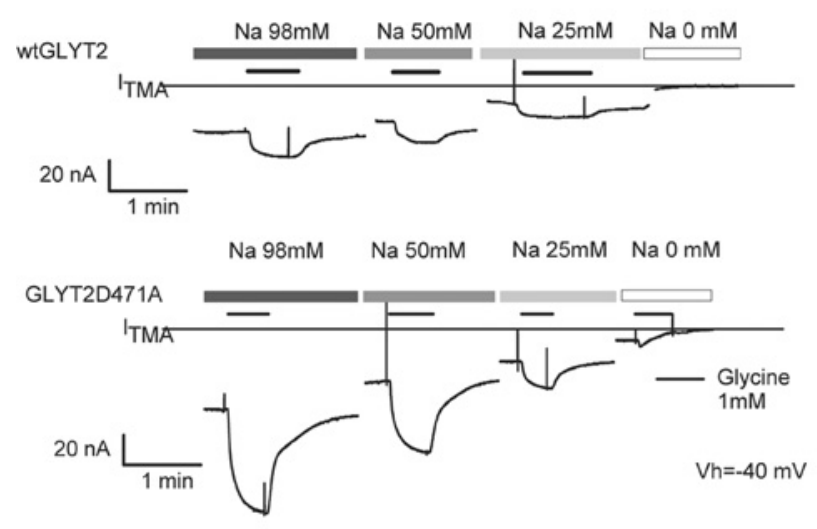

B

\section{GLYT1}

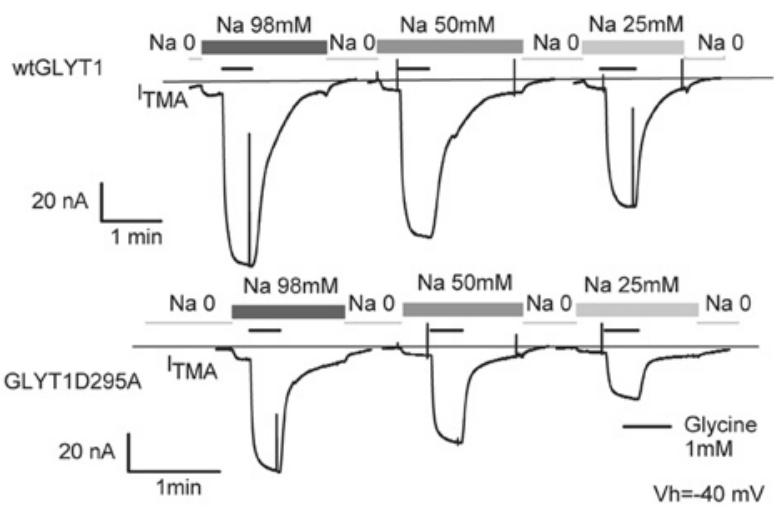

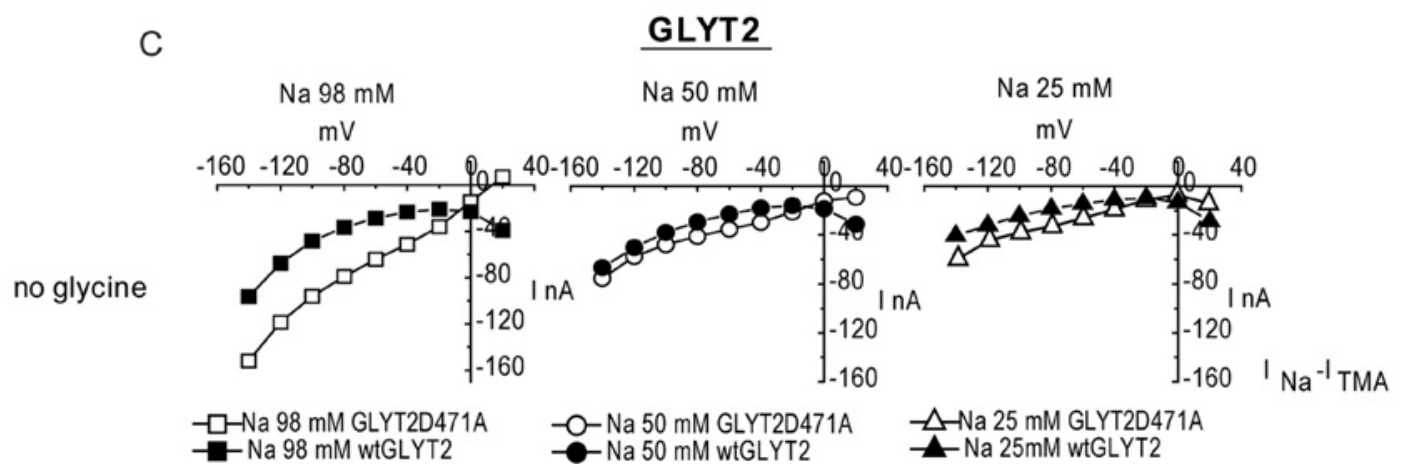

Figure 3 Electrophysiological characterization of the GLYT2D471A and GLYT1D295A mutants

(A and B) Inward currents recorded at a holding potential of $-40 \mathrm{mV}$ elicited by application of $1 \mathrm{mM}$ glycine at the indicated sodium concentrations in four representative oocytes expressing wIGLYT2 or GLYT2D471A (in A), and wtGLYT1 or GLYT1D295A (in B). The zero current level (the current in the presence of $98 \mathrm{mM}$ TMA, I ImA) is shown by the long horizontal line. (C) Current-voltage relationship of leak currents in wtGLYT2 and GLYT2D471A. From a holding potential of $-40 \mathrm{mV}$, pulses of $20 \mathrm{mV}$ and $400 \mathrm{~ms}$ ranging from $-140 \mathrm{mV}$ to $+20 \mathrm{mV}$ were applied to oocytes expressing the protein. The steady-state currents measured at each potential were plotted after subtracting the traces recorded in $98 \mathrm{mM}$ TMA chloride from traces recorded in the presence of the indicated sodium concentration. Data were collected in the presence of the indicated sodium concentration and in the absence of glycine.

suggest that $\mathrm{Asp}^{471}$ neutralization interferes with cation access to the GLYT2 Na2 site.

\section{Accessibility to MTS reagents of cysteine residues introduced at positions 471 (GLYT2) and 295 (GLYT1)}

The control of cation access may be modulated by positions sensitive to the presence of cations. We introduced cysteine residues into the homologous GLYT2 and GLYT1 target positions under study and tested their external accessibility to impermeant MTS derivatives, specific thiol reagents, subsequently analysing transporter activity and surface labelling [38] (the strategy used for these experiments is illustrated in Supplementary Figure S2 at http://www.BiochemJ.org/bj/442/bj4420323add.htm). Although a D471C mutant was used for GLYT2, which is resistant to MTS reagents, the MTS-resistant GLYT1C62A mutant was used to define the GLYT1 background $[5,39,40]$. The cysteine residues introduced at the target positions were externally accessible in both transporters and bound all of the MTS reagents assayed, including the positively charged MTSET, the negatively charged MTSES and a biotin-coupled MTS derivative (MTSEA- biotin). Non-cysteine amino acid substitutions at the target positions yielded MTS-resistant transporters such as wtGLYT2 or GLYT1C62A, demonstrating that the cysteine residues introduced were indeed reactive (Supplementary Figure S2B).

Transport activity of the two cysteine mutants was inhibited by MTS reaction (Figure 7), although cations produced opposite effects in GLYT2 (Figure 7A) and GLYT1 (Figure 7B; attenuation of inhibition in the GLYT2 mutant and increased inhibition, especially by $\mathrm{Na}^{+}$, in the GLYT1 mutant). These opposing effects were more evident when analysing MTSES inhibition, suggesting better reagent access due to its negative charge and slightly smaller size (Figures 7C and 7D) [41]. This was confirmed by the greater decrease in MTSEA-biotin binding seen following preincubation with MTSES rather than MTSET in HBS (Figure 7F), despite using equally reactive concentrations of each reagent [38]. This experiment also confirms that all three reagents bind to the same exogenous cysteine residue. The protection offered by cations against the inhibition of GLYT2D471C transport was maintained at low temperatures (incubation with the reagent at $4{ }^{\circ} \mathrm{C}$; Figure $7 \mathrm{E}$ ), suggesting that only minor conformational changes are required to induce protection, or that sodium binding and $\mathrm{D} 471 \mathrm{C}$ protection occur at sites in close proximity. These 


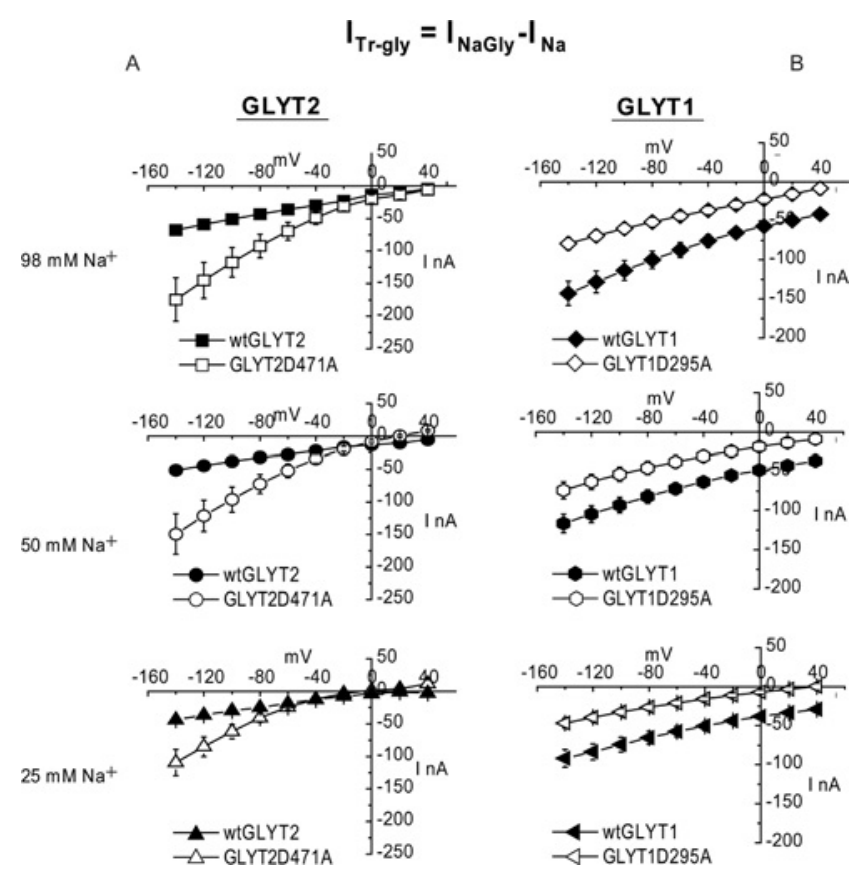

Figure 4 Current-voltage plots of net transport currents $\left(I_{\text {Tr_Gly }}=I_{\text {Na_Gly }}-I_{\mathrm{Na}}\right)$ of the GLYT2D471A and GLYT1D295A mutants

Net transport currents: the same protocol as in Figure 3(C) was applied to 0ocytes expressing the transporter indicated. At each sodium concentration, the steady-state currents measured in the presence of $1 \mathrm{mM}$ glycine at each potential were plotted after subtracting traces recorded with the same concentration of $\mathrm{NaCl}$ alone. (B) Calculation of GLYT1 $K_{0.5 \text { Naltr }}$ for sodium at each voltage assayed indicated a lower $\mathrm{Na}^{+}$affinity for the mutant at potentials more positive than $-60 \mathrm{mV}$. (A) In the GLYT2 mutant, $\mathrm{Na}^{+}$affinity was lower than that of the wt at potentials more positive than $-100 \mathrm{mV}$.

findings may be compatible with the location of $\mathrm{Asp}^{471}$ close to an $\mathrm{Na}^{+}$-interaction site.

When we analysed the binding of MTSEA-biotin, which measures the actual accessibility of the target positions (and not the resulting transport), we found differences between the GLYT2 and GLYT1 cysteine mutants (Figure 8). In accordance with the cation effects on transport inhibition by the MTS, a small protective effect of MTSEA-biotin binding was detected at low $\mathrm{Na}^{+}$concentrations $(0-50 \mathrm{mM})$ in the GLYT2 mutant, suggesting that protection of transport is achieved by preventing MTS binding to a position 471 conformation acquired upon high-affinity binding of $\mathrm{Na}^{+}$(Figures 7A, 7C, 7E and 8A). This may represent a transient conformation [16]. In contrast, $\mathrm{Na}^{+}$increased MTSEA-biotin binding in the GLYT1 mutant, in agreement with the potentiating effect of sodium on transport inhibition (Figures 7B, 7D and 8A). The accessibility of the target positions was also lithium-sensitive (Figures 8C and 8D) and the dose-responses to lithium and sodium revealed an interesting aspect: after the protection elicited at low concentrations, both cations exposed position 471 of GLYT2, probably via cationdriven conformational changes. This suggests that both $\mathrm{Na}^{+}$ and $\mathrm{Li}^{+}$induce a common transport-competent conformation in GLYT2. However, GLYT1C295 was exposed by $\mathrm{Na}^{+}$but occluded by $\mathrm{Li}^{+}$, suggesting that lithium may induce an inhibitory conformation, consistent with the inhibitory effect of $\mathrm{Li}^{+}$on this transporter. Moreover, these effects were temperature-sensitive, as was the case for cation-induced conformational changes (Figures 8E and 8F). Thus positions GLYT2471 and GLYT1295 are conformationally active in addition to displaying cation sensitivity.
A

B
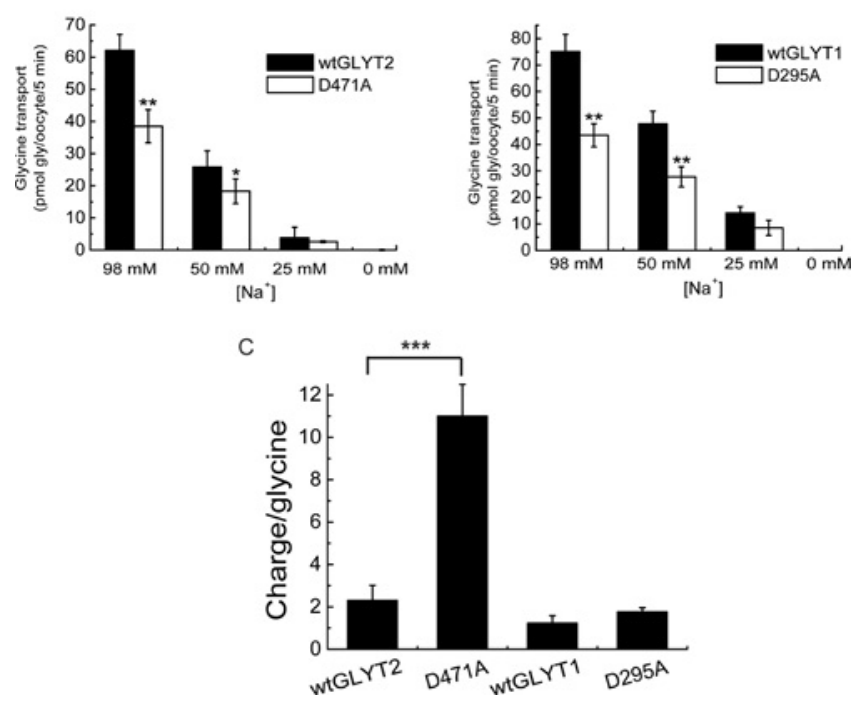

Figure 5 Glycine transport and ion-substrate coupling of the GLYT2D471A and GLYT1D295A mutants in oocytes

(A and B) Control oocytes or oocytes expressing the indicated transporters were assayed for $\left.{ }^{3} \mathrm{H}\right]$ glycine transport $\left(100 \mu \mathrm{M}\right.$ final concentration, specific activity $1.1 \mathrm{MBq} \cdot \mathrm{mmol}^{-1}$ ) over 5 min in external control solution containing the indicated $\mathrm{NaCl}$ concentration isotonically replaced by TMA chloride ( $n=5$ per condition). The concentration of glycine (pmol) accumulated in control oocytes was subtracted from that of cRNA-expressing oocytes and the result was plotted against the concentration of sodium present in the assay. (C) Current was continuously monitored in a single oocyte expressing the indicated transporters clamped at a holding potential of $-40 \mathrm{mV}$. A stable baseline current was established in $98 \mathrm{mM}$ $\mathrm{NaCl}$ before superfusing $100 \mu \mathrm{M}\left[{ }^{3} \mathrm{H}\right] \mathrm{glycine}$ for $5 \mathrm{~min}$ and washing out with the same buffer without the tracer. The induced current was monitored during the incubation period and the total accumulated glycine was subsequently quantified. The total current was converted into charge and the net charge movement per translocated glycine molecule was plotted. ${ }^{*} P<0.05$; ${ }^{\star \star} P<0.01 ;{ }^{* \star \star} P<0.001$ with respect to wt (two-tailed Student's $t$ test).

\section{DISCUSSION}

Since the elucidation of the three dimensional structure of Leu $_{\mathrm{Aa}}[11]$, homology models have represented valuable tools to study the structure of the SLC6 transporters, revealing that family members show similar, but not identical, structures to the prokaryotic homologue template $[10,15,42]$. Glycine transporters share $50 \%$ sequence identity, but exhibit differing sodium/substrate stoichiometry, an interesting feature that may contribute to the singularity of their structures. We recently generated GLYT1 and GLYT2 homology models that predicted the conservation of the two sodium sites ( $\mathrm{Na} 1$ and $\mathrm{Na} 2)$ present in the template, and we confirmed their validity by mutagenesis and functional analysis [18]. To identify the additional sodium coupling ion in GLYT2, the models were subjected to molecular dynamics simulations in the presence of $\mathrm{Na}^{+}$. Calculated MIP maps and in silico mutagenesis revealed a conserved region in the GLYT2 external vestibule that displayed a high probability of interacting with $\mathrm{Na}^{+}$. Three aspartate residues within this region $\left(\mathrm{Asp}^{471}, \mathrm{Asp}^{542}\right.$ and $\mathrm{Asp}^{635}$ ) exhibited the highest MIP for $\mathrm{Na}^{+}$ions, and these values were reduced strongly by in silico substitutions. Mutagenesis analysis demonstrated that all three of these residues were crucial for glycine transport. All Asp $^{635}$ substitution mutants were inactive, in accordance with its proposed role in the transporter external gate [11]. Similarly, all $\mathrm{Asp}^{542}$ mutants were inactive, with the exception of the most conservative substitution, which exhibited a functional wt-like phenotype. Asp $\mathrm{p}^{471}$ mutations were partially tolerated, and, despite 

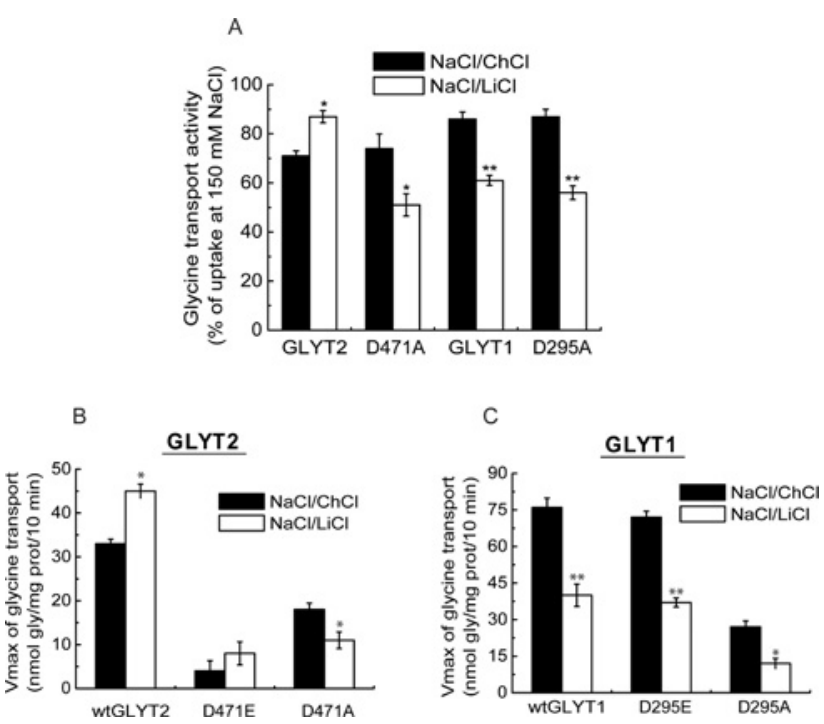

Figure 6 Effect of lithium on glycine transport by the GLYT1 and GLYT2 mutants

COS7 cells expressing the indicated transporters were assayed for ${ }^{3}[\mathrm{H}]$ glycine transport $(10 \mu \mathrm{M}$, final glycine concentration) in $\mathrm{HBS}$ containing $150 \mathrm{mM} \mathrm{NaCl}$ (no substitution, $100 \%$ of transport in A), $50 \mathrm{mM} \mathrm{NaCl}+100 \mathrm{mM}$ choline chloride ( $\mathrm{NaCl} / \mathrm{ChCl}$, closed bars) or $50 \mathrm{mM}$ $\mathrm{NaCl}+100 \mathrm{mM} \mathrm{LiCl}(\mathrm{NaCl} / \mathrm{LiCl}$, open bars; $\mathbf{A}-\mathbf{C})$. (A) The transport activity obtained by isotonically substituting two-thirds of the $\mathrm{NaCl}$ concentration $(100 \mathrm{mM})$ with either $\mathrm{ChCl}$ or $\mathrm{LiCl}$ is expressed as a percentage of transport at $150 \mathrm{mM} \mathrm{NaCl}$. The $100 \%$ glycine transport values in nmol of glycine/mg of protein per 10 min were as follows: GLYT2, 3.4 + 0.3; D471A, $0.96 \pm 0.2 ; \mathrm{GLYT1}, 5.3 \pm 0.5 ; \mathrm{D} 295 \mathrm{~A}, 0.92 \pm 0.1$. (B and C) $V_{\max }$ values for glycine transport induced by $\mathrm{NaCl} / \mathrm{ChCl}$ or $\mathrm{NaCl} / \mathrm{LiCl}$ in wtGLYT2 and $\mathrm{Asp}^{471}$ mutants (B), and in wtGLYT1 and Asp 295 mutants (C). ${ }^{\star} P<0.05 ;{ }^{\star \star} P<0.01$ with respect to choline substitution (Student's $t$ test).

the fact that this feature may suggest that the residue is dispensable for transport, functional analysis revealed reduced affinity and apparent co-operativity for $\mathrm{Na}^{+}$as measured by radiotracer flux assays, in comparison with the homologous ( Asp $^{295}$ ) mutation in GLYT1. We therefore undertook the study of the functional role of $\mathrm{Asp}^{471}$.

Electrophysiological characterization of the D471A mutant revealed an enhanced constitutive transport-independent conductance in the absence of substrate, consistent with the $\mathrm{Na}^{+}$ leak current reported previously in wtGLYT2 [4]. This behaviour was not observed for the corresponding GLYT1 mutation. The leakage current increased with negative voltage and increasing sodium concentration, and it was reversed in the GLYT2 mutant at high sodium concentrations. Although the results suggest that the leak current is carried by $\mathrm{Na}^{+}$ions, this hypothesis remains to be confirmed. Mutation of homologous aspartate residues in GLYTs produced opposing effects on transportassociated currents: a reduction for GLYT1 and an increase for GLYT2. Simultaneous measurement of current and $\left[{ }^{3} \mathrm{H}\right]$ glycine accumulation in the same oocyte revealed that the $\mathrm{Asp}^{471}$ mutation increased non-stoichiometric or uncoupled ion movements carried by GLYT2, indicative of defective ion coupling in this mutant. This observation suggests this aspartate residue is involved in coupling $\mathrm{Na}^{+}$and glycine fluxes in GLYT2, but not in GLYT1.

The increased leakage and uncoupling of the D471A mutant is compatible with the mechanism proposed to generate uncoupled currents in SERT (serotonin transporter) by modulating the relative distances and orientation of TM1-TM6 residues [43], and with the coupling of $\mathrm{Cl}^{-}$binding to transport [14,44]. However, it remains unknown whether the substrate-dependent
A
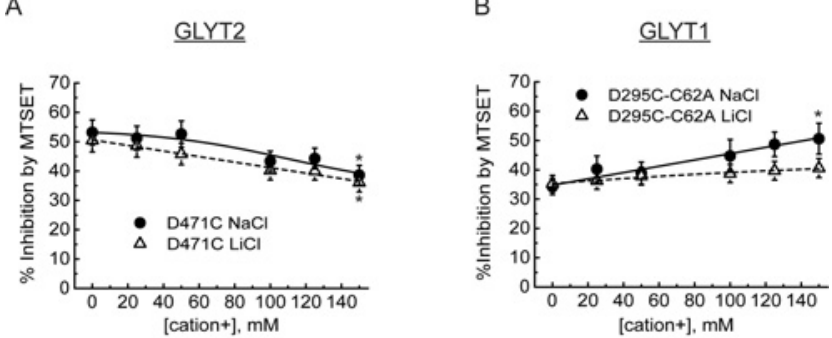

C

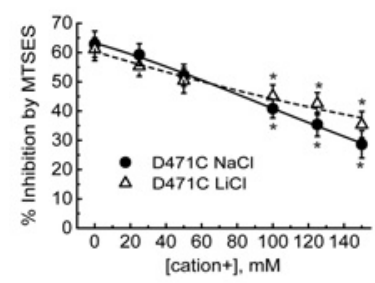

D
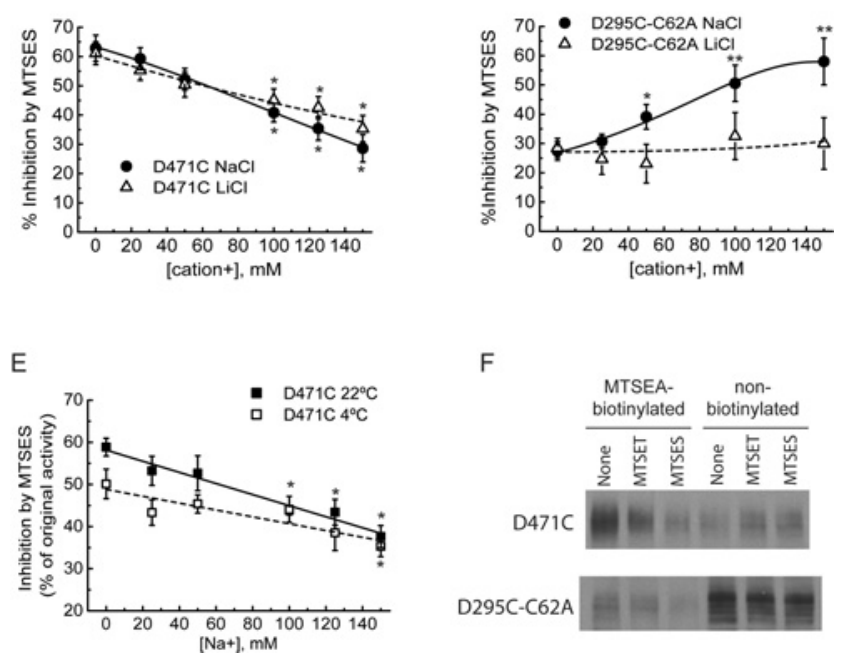

Figure 7 Effect of cations on MTSET and MTSES sensitivity in mutants with target cysteine residues in GLYT2-Asp ${ }^{471}$ and GLYT1-Asp 295

C0S7 cells expressing D471C (A and C) or D295C/C62A (B and D) were treated at $22^{\circ} \mathrm{C}$ with $0.2 \mathrm{mM}$ MTSET (A and B) or with 0.6 mM MTSES (C and D) in HBS containing the indicated cation $\left(\mathrm{Na}^{+}\right.$or $\mathrm{Li}^{+}$) concentrations (choline chloride substitution). After a $10 \mathrm{~min}$ incubation, the cells were washed and glycine transport was determined in $\mathrm{NaCl}$-containing HBS. MTS inhibition of glycine transport is expressed as the fraction of the uptake inhibited [100 - (100xuptake after MTS/uptake before MTS)]. The 100\% transport values (nmol of glycine/mg of protein per $10 \mathrm{~min}$ ) were $0.92 \pm 0.3(\mathrm{D} 471 \mathrm{C})$ and $0.59 \pm 0.1$ (D295C/C62A). (E) Experimental conditions as in $(\mathbf{A})$ but where cells expressing $\mathrm{D} 471 \mathrm{C}$ were treated at $22^{\circ} \mathrm{C}$ with $0.5 \mathrm{mM}$ MTSES and at $4^{\circ} \mathrm{C}$ with $1 \mathrm{mM}$ MTSES in HBS containing the indicated concentrations of $\mathrm{Na}^{+}$, and were assayed for transport at $10 \mu \mathrm{M}$ glycine in $\mathrm{NaCl} / \mathrm{HBS}$. The effect of MTSES on uptake is expressed as in (C). ${ }^{*} P<0.05 ;{ }^{* \star} P<0.01$ with respect to $0 \mathrm{mM}$ cation (Student's $t$ test). (F) MTSEA-biotin labelling after a 10 min pre-incubation with HBS (containing no MTS reagent), $1 \mathrm{mM}$ MTSET or $10 \mathrm{mM}$ MTSES. After pre-incubation, the cells were processed as described in the Experimental section.

and -independent currents share a common pathway and/or molecular contacts as they permeate the transporter. Since both processes are affected by a point mutation, they may share a common pathway. The observed effects of lithium on aspartate mutants also support this hypothesis: neutralization of $\mathrm{Asp}^{471}$ altered the effect of lithium on GLYT2 transport, resulting in inhibition rather than stimulation of the mutant by the cation, whereas the D295A mutant exhibited the same inhibitory response to lithium as its corresponding wt control. A similar phenotypic change is produced upon mutation of residues associated with the $\mathrm{Na} 2$ site of GLYT2 [18], further reinforcing the link between $\mathrm{Asp}^{471}$ and the $\mathrm{Na} 2$ site, and suggesting that neutralization of Asp ${ }^{471}$ interferes with the access of cations to the GLYT2 Na2 site. Alteration of the proper allosteric connection between $\mathrm{Na} 1$ ( $\mathrm{Na}^{+}$-bound) and $\mathrm{Na} 2\left(\mathrm{Li}^{+}\right.$-bound) sites, which is required for the stimulatory effect of lithium at GLYT2, could explain the mutant's behaviour. Alternatively, the decreased affinity for sodium in the mutant may result in similar $\mathrm{Na}^{+}$and $\mathrm{Li}^{+}$affinities, thereby 

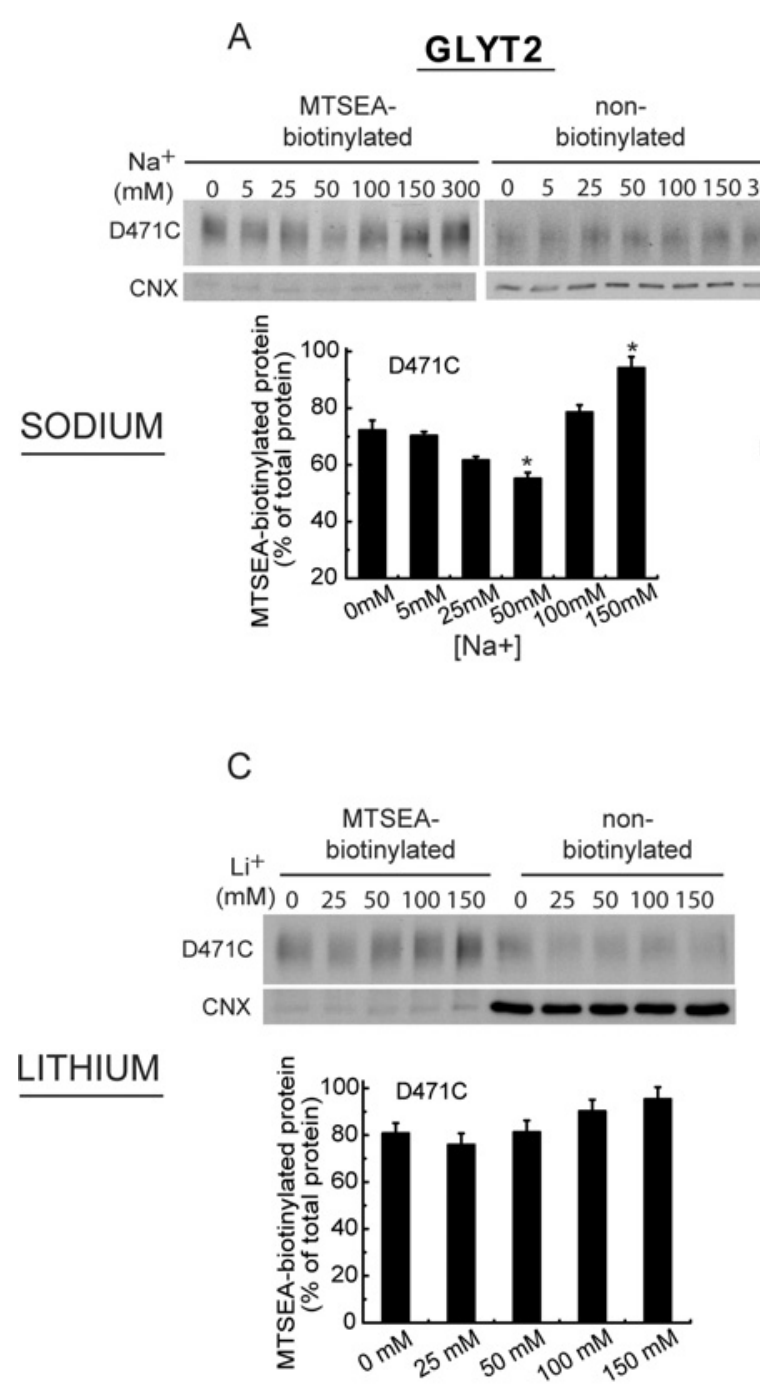

$[\mathrm{Li+}]$

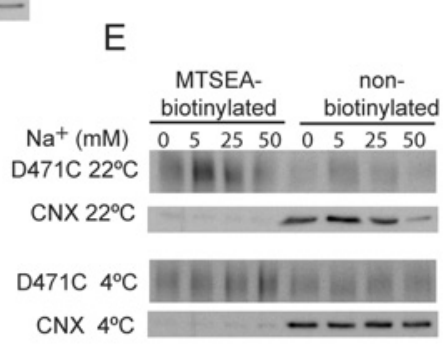

$\mathrm{F}$

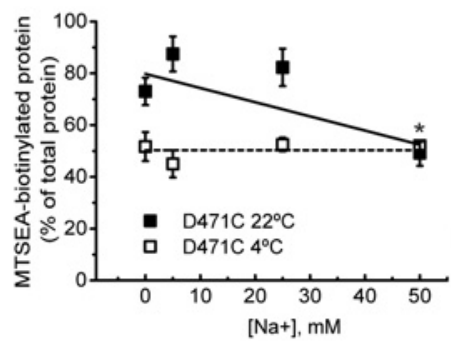

B

GLYT1

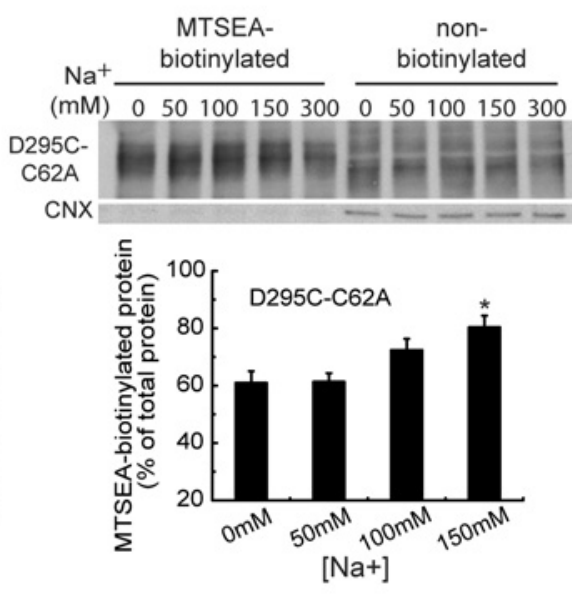

D
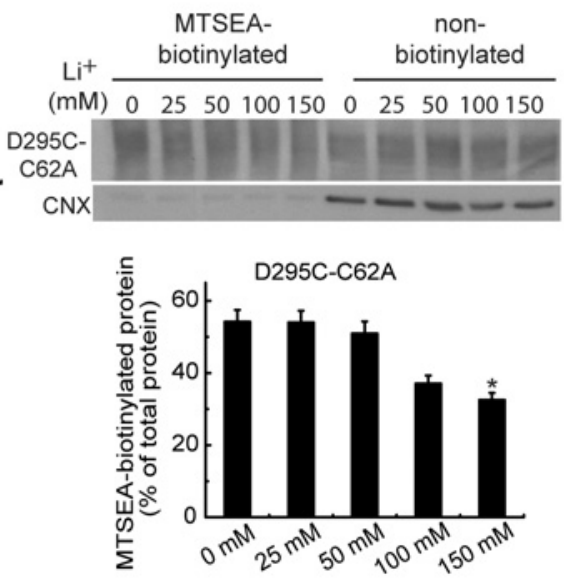

$[\mathrm{Li}+]$

\section{Figure 8 Cation-dependence of MTSEA-biotin accessibility in mutants with target cysteine residues at GLYT2-Asp ${ }^{471}$ and GLYT1-Asp ${ }^{295}$}

COS7 cells expressing D471C (A and C) or D295C/C62A (B and D) were treated at $22^{\circ} \mathrm{C}$ with $0.5 \mathrm{mM} \mathrm{MTSEA-biotin} \mathrm{in} \mathrm{HBS} \mathrm{containing} \mathrm{the} \mathrm{indicated} \mathrm{concentrations} \mathrm{of} \mathrm{Na}^{+}(\mathbf{A}$ and $\mathbf{B})$ or $\mathrm{Li}^{+}(\mathbf{C}$ and $\mathbf{D}$; choline chloride substitution), then washed, and streptavidin-bound proteins were detected by immunoblotting (60 or $4 \mu \mathrm{g}$ of biotinylated or non-biotinylated proteins were loaded per lane respectively). CNX, calnexin loading control. Upper panels in (A-D): representative Western blots. Lower panels in (A-D): densitometric analysis of the average values of three or four independent Western blots. (E and $\mathbf{F}$ ) Cells expressing D471C were labelled at $22^{\circ} \mathrm{C}$ or $4^{\circ} \mathrm{C}$ with $0.5 \mathrm{mM}$ MTSEA-biotin in HBS with the indicated Na ${ }^{+}$concentrations, then washed, and streptavidin-bound proteins were detected in immunoblots (60 or $4 \mu \mathrm{g}$ of biotinylated or non-biotinylated proteins were loaded per lane respectively). ${ }^{*} P<0.05$ with respect to $0 \mathrm{mM}$ cation (Student's $t$ test).

reducing the selectivity for $\mathrm{Na}^{+}$[45]. The similar magnitude of protection of D471C MTS inhibition by $\mathrm{Na}^{+}$and $\mathrm{Li}^{+}$suggests a comparable affinity for the two cations. The most conservative mutation of $\mathrm{Asp}^{471}$ to glutamic acid, although reducing the $\mathrm{Na}^{+}$affinity, did not alter the $\mathrm{Li}^{+}$response when compared with wtGLYT2, suggesting a less dramatic alteration of cation selectivity or of the conformational connections between $\mathrm{Na}^{+}$ sites.

MTS accessibility suggests a role for Asp ${ }^{471}$ in maintaining a conformational connection with the $\mathrm{Na} 2$ site, probably mediating the conformational changes necessary for translocation to occur. MTSES inhibition and protection by $\mathrm{Na}^{+}$of D471C was easier than that of MTSET, probably due to the greater accessibility of a negatively charged reagent in the presence of bound sodium. MTSEA-biotin displacement by MTSES, and the persistence of $\mathrm{Na}^{+}$protection at $4{ }^{\circ} \mathrm{C}$, suggests that MTSES binding is prevented by the direct physical occlusion by $\mathrm{Na}^{+}$of the target cysteine residue. However, sodium protection of binding of the bulkier MTSEA-biotin to D471C was lost at $4^{\circ} \mathrm{C}$, indicating that cation binding induces conformational changes that occlude $\mathrm{Cys}^{471}$. This finding demonstrates that position 471 is conformationally active, as well as cation-sensitive. Moreover, this appears not to be exclusive to the 471 (GLYT2) position, as accessibility of the homologous 295 (GLYT1) position to MTS compounds was also modified by the presence of $\mathrm{Na}^{+}$and $\mathrm{Li}^{+}$, with differing consequences for each transporter. Although saturating concentrations of $\mathrm{Na}^{+}$and $\mathrm{Li}^{+}$exposed position 471 (GLYT2), probably inducing a common transport-competent conformation, position 295 (GLYT1) was exposed by $\mathrm{Na}^{+}$but occluded by $\mathrm{Li}^{+}$, suggesting that the latter induces a transportinhibitory conformation. This interpretation is in agreement with previous reports implicating several SLC6 external vestibule 
residues in conformational changes following lithium binding $[36,37,46]$.

In summary, $\mathrm{Asp}^{471}$ in GLYT2 is a key residue selected after molecular dynamics simulations and subsequent in silico mutagenesis on the basis of high MIP maps, which were consistent with a highly probable and well localized $\mathrm{Na}^{+}$-like binding site (Figure 1). $\mathrm{Na}^{+}$-binding energy values were sufficiently stable to accommodate the ion in an adequate environment [47]. Similar results have been reported for glutamate [48] and leucine [49] transporters, suggesting that a pre-formed cavity exists in the initial model, and, as simulation progresses, the protein itself conforms a favourable environment for $\mathrm{Na}^{+}$. We found that $\mathrm{Asp}^{471}$ plays a key role in $\mathrm{Na}^{+}$affinity and $\mathrm{Na}^{+}$-glycine coupling during co-transport. Moreover, $\mathrm{Asp}^{471}$ mutation induced $\mathrm{Na}^{+}$leakage and affected $\mathrm{Na}^{+}$selectivity with respect to $\mathrm{Li}^{+}$. $\mathrm{Asp}^{471}$ is a cationsensitive and conformationally active residue involved in $\mathrm{Na}^{+}$and $\mathrm{Li}^{+}$-induced conformational changes. We propose a role for $\mathrm{Asp}^{471}$ in controlling cation access to GLYT2 $\mathrm{Na}^{+}$sites, as well as ion coupling and the induction of subsequent conformational changes. Some of these features may be compatible with the expected properties of the $\mathrm{Na} 3$ site, including its proximity to the external gate of the transporter. However, the affinity values of approximately $-5 \mathrm{kcal} / \mathrm{mol}(1 \mathrm{kcal}=4.184 \mathrm{~kJ})$ resulting from our computational studies are indicative of low-affinity sites that can interchange ions $\left(\right.$ as $\mathrm{Li}^{+}$or $\mathrm{K}^{+}$) with the bulk solvent $[48,49]$. Moreover, as the sodium leakage and uncoupling that occurs in $\mathrm{Asp}^{471}$ mutants prevents the measurement of $\mathrm{Na}^{+}$-glycine stoichiometry, further studies will be required to determine whether this is a true $\mathrm{Na}^{+}$site or merely a modulatory site.

\section{AUTHOR CONTRIBUTION}

Carmen Aragón, Ángel Ortíz and Beatriz López-Corcuera designed the research. Gonzalo Pérez-Siles, Enrique Núñez and Esperanza Jiménez performed biochemical experiments. Alejandra Leo-Macías, Guillermo Pita and Antonio Morreale performed the bioinformatics and computational studies. Francesca Cherubino, Rachele Sangaletti and Elena Bossi performed electrophysiological characterization. Enrique Núñez performed charge/flux ratio experiments. Gonzalo Pérez-Siles, Antonio Morreale, Carmen Aragón, Ángel Ortíz and Beatriz López-Corcuera analysed data. Beatriz López-Corcuera wrote the paper.

\section{ACKNOWLEDGEMENTS}

We are grateful to Dr Antonio Peres for critical reading of the paper and valuable suggestions. Jaime de Juan-Sanz is acknowledged for help with generating the cRNAs. Professor Cecilio Giménez is gratefully acknowledged for generous help in determining the charge/flux ratios.

\section{FUNDING}

This work was supported by the Spanish Dirección General de Enseñanza Superior e Investigación Científica [grant numbers BFU2005-05931/BMC and BI02005-05786], Ministerio de Ciencia e Innovación [grant number SAF2008-05436], Comunidad Autónoma de Madrid [grant numbers 11/BCB/010 and S-SAL-0253/2006], and an institutional grant from the Fundación Ramón Areces. The research group is a member of the Network for Cooperative Research on Membrane Transport Proteins (REIT), cofunded by the Ministerio de Educación y Ciencia, Spain and the European Regional Development Fund (ERDF) [grant number BFU2007-30688-E/BFI]. A.M. acknowledges the Comunidad Autónoma-de-Madrid for financial support through the AMAROUTO program to the Fundación Severo Ochoa.

\section{REFERENCES}

1 Aragon, C. and Lopez-Corcuera, B. (2003) Structure, function and regulation of glycine neurotransporters. Eur. J. Pharmacol. 479, 249-262

2 Gomeza, J., Hulsmann, S., Ohno, K., Eulenburg, V., Szoke, K., Richter, D. and Betz, H. (2003) Inactivation of the glycine transporter 1 gene discloses vital role of glial glycine uptake in glycinergic inhibition. Neuron $\mathbf{4 0}, 785-796$
3 Lopez-Corcuera, B., Martinez-Maza, R., Nunez, E., Roux, M., Supplisson, S. and Aragon, C. (1998) Differential properties of two stably expressed brain-specific glycine transporters. J. Neurochem. 71, 2211-2219

4 Roux, M. J. and Supplisson, S. (2000) Neuronal and glial glycine transporters have different stoichiometries. Neuron 25, 373-383

5 Roux, M. J., Martinez-Maza, R., Le Goff, A., Lopez-Corcuera, B., Aragon, C. and Supplisson, S. (2001) The glial and the neuronal glycine transporters differ in their reactivity to sulfhydryl reagents. J. Biol. Chem. 276, 17699-17705

6 Cherubino, F., Bossi, E., Miszner, A., Ghezzi, C. and Peres, A. (2010) Transient currents in the glycine cotransporter GlyT1 reveal different steps in transport mechanism. J. Mol. Neurosci. 41, 243-251

7 Harvey, R. J., Topf, M., Harvey, K. and Rees, M. I. (2008) The genetics of hyperekplexia: more than startle! Trends Genet. 24, 439-447

8 Gomeza, J., Ohno, K., Hulsmann, S., Armsen, W., Eulenburg, V., Richter, D. W., Laube, B. and Betz, H. (2003) Deletion of the mouse glycine transporter 2 results in a hyperekplexia phenotype and postnatal lethality. Neuron $\mathbf{4 0}, 797-806$

9 Aragon, C. and Lopez-Corcuera, B. (2005) Glycine transporters: crucial roles of pharmacological interest revealed by gene deletion. Trends Pharmacol. Sci. 26, 283-286

10 Beuming, T., Shi, L., Javitch, J. A. and Weinstein, H. (2006) A comprehensive structure-based alignment of prokaryotic and eukaryotic neurotransmitter/ $/ \mathrm{Na}^{+}$ symporters (NSS) aids in the use of the LeuT structure to probe NSS structure and function. Mol. Pharmacol. 70, 1630-1642

11 Yamashita, A., Singh, S. K., Kawate, T., Jin, Y. and Gouaux, E. (2005) Crystal structure of a bacterial homologue of $\mathrm{Na}^{+} / \mathrm{Cl}^{-}$-dependent neurotransmitter transporters. Nature $\mathbf{4 3 7}$ 215-223

12 Zomot, E., Bendahan, A., Quick, M., Zhao, Y., Javitch, J. A. and Kanner, B. I. (2007) Mechanism of chloride interaction with neurotransmitter:sodium symporters. Nature $\mathbf{4 4 9}$ 726-730

13 Forrest, L. R., Tavoulari, S., Zhang, Y. W., Rudnick, G. and Honig, B. (2007) Identification of a chloride ion binding site in $\mathrm{Na}^{+} / \mathrm{Cl}^{-}$-dependent transporters. Proc. Natl. Acad. Sci. U.S.A. 104, 12761-12766

14 Ben-Yona, A., Bendahan, A. and Kanner, B. I. (2011) A glutamine residue conserved in the neurotransmitter:sodium:symporters is essential for the interaction of chloride with the GABA transporter GAT-1. J. Biol. Chem. 286, 2826-2833

15 Forrest, L. R., Zhang, Y. W., Jacobs, M. T., Gesmonde, J., Xie, L., Honig, B. H. and Rudnick, G. (2008) Mechanism for alternating access in neurotransmitter transporters. Proc. Natl. Acad. Sci. U.S.A. 105, 10338-10343

16 Shi, L., Quick, M., Zhao, Y., Weinstein, H. and Javitch, J. A. (2008) The mechanism of a neurotransmitter:sodium symporter - inward release of $\mathrm{Na}^{+}$and substrate is triggered by substrate in a second binding site. Mol. Cell $\mathbf{3 0}, 667-677$

17 Vandenberg, R. J., Shaddick, K. and Ju, P. (2007) Molecular basis for substrate discrimination by glycine transporters. J. Biol. Chem. 282, 14447-14453

18 Perez-Siles, G., Morreale, A., Leo-Macias, A., Pita, G., Ortiz, A. R., Aragon, C. and Lopez-Corcuera, B. (2011) Molecular basis of the differential interaction with lithium of glycine transporters GLYT1 and GLYT2. J. Neurochem. 118, 195-204

19 Eddy, S. R. (1998) Profile hidden Markov models. Bioinformatics 14, 755-763

20 Altschul, S. F., Madden, T. L., Schaffer, A. A., Zhang, J., Zhang, Z., Miller, W. and Lipman D. J. (1997) Gapped BLAST and PSI-BLAST: a new generation of protein database search programs. Nucleic Acids Res. 25, 3389-3402

21 Sali, A. and Blundell, T. L. (1993) Comparative protein modelling by satisfaction of spatial restraints. J. Mol. Biol. 234, 779-815

22 Humphrey, W., Dalke, A. and Schulten, K. (1996) VMD: visual molecular dynamics. J. Mol. Graphics 14, 33-38

23 Phillips, J. C., Braun, R., Wang, W., Gumbart, J., Tajkhorshid, E., Villa, E., Chipot, C., Skeel, R. D., Kalé, L. and Schulten, K. (2005) Scalable molecular dynamics with NAMD. J. Comput. Chem. 26, 1781-1802

24 Baker, N. A., Sept, D., Joseph, S., Holst, M. J. and McCammon, J. A. (2001) Electrostatics of nanosystems: application to microtubules and the ribosome. Proc. Natl. Acad. Sci. U.S.A. 98, 10037-10041

25 Eisen, M. B., Spellman, P. T., Brown, P. O. and Botstein, D. (1998) Cluster analysis and display of genome-wide expression patterns. Proc. Natl. Acad. Sci. U.S.A. 95, 14863-14868

26 de Hoon, M. J., Imoto, S., Nolan, J. and Miyano, S. (2004) Open source clustering software. Bioinformatics 20, 1453-1454

27 Liu, Q. R., Lopez-Corcuera, B., Mandiyan, S., Nelson, H. and Nelson, N. (1993) Cloning and expression of a spinal cord- and brain-specific glycine transporter with novel structural features. J. Biol. Chem. 268, 22802-22808

28 Smith, K. E., Borden, L. A., Hartig, P. R., Branchek, T. and Weinshank, R. L. (1992) Cloning and expression of a glycine transporter reveal colocalization with NMDA receptors. Neuron 8, 927-935

29 Fornes, A., Nunez, E., Aragon, C. and Lopez-Corcuera, B. (2004) The second intracellular loop of the glycine transporter 2 contains crucial residues for glycine transport and phorbol ester-induced regulation. J. Biol. Chem. 279, 22934-22943 
30 Bossi, E., Fabbrini, M. S. and Ceriotti, A. (2007) Exogenous protein expression in Xenopus 0ocytes: basic procedures. Methods Mol. Biol. 375, 107-131

31 L00, D. D., Eskandari, S., Boorer, K. J., Sarkar, H. K. and Wright, E. M. (2000) Role of $\mathrm{Cl}^{-}$in electrogenic $\mathrm{Na}^{+}$-coupled cotransporters GAT1 and SGLT1. J. Biol. Chem. 275, 37414-37422

32 Zafra, F., Gomeza, J., Olivares, L., Aragon, C. and Gimenez, C. (1995) Regional distribution and developmental variation of the glycine transporters GLYT1 and GLYT2 in the rat CNS. Eur. J. Neurosci. 7, 1342-1352

33 Fornes, A., Nunez, E., Alonso-Torres, P., Aragon, C. and Lopez-Corcuera, B. (2008) Trafficking properties and activity regulation of the neuronal glycine transporter GLYT2 by protein kinase C. Biochem. J. 412, 495-506

34 Rosenberg, A. and Kanner, B. I. (2008) The substrates of the $\gamma$-aminobutyric acid transporter GAT-1 induce structural rearrangements around the interface of transmembrane domains 1 and 6. J. Biol. Chem. 283, 14376-14383

35 Andrini, 0., Ghezzi, C., Murer, H. and Forster, I. C. (2008) The leak mode of type II $\mathrm{Na}^{+}-\mathrm{P}_{\mathrm{i}}$ cotransporters. Channels 2, 346-357

36 MacAulay, N., Zeuthen, T. and Gether, U. (2002) Conformational basis for the $\mathrm{Li}^{+}$-induced leak current in the rat $\gamma$-aminobutyric acid (GABA) transporter-1. J. Physiol. 544, 447-458

37 Zhou, Y., Zomot, E. and Kanner, B. I. (2006) Identification of a lithium interaction site in the $\gamma$-aminobutyric acid (GABA) transporter GAT-1. J. Biol. Chem. 281, 22092-22099

38 Karlin, A. and Akabas, M. H. (1998) Substituted-cysteine accessibility method. Methods Enzymol. 293, 123-145

39 Lopez-Corcuera, B., Nunez, E., Martinez-Maza, R., Geerlings, A. and Aragon, C. (2001) Substrate-induced conformational changes of extracellular loop 1 in the glycine transporter GLYT2. J. Biol. Chem. 276, 43463-43470

40 Yu, N., Cao, Y., Mager, S. and Lester, H. A. (1998) Topological localization of cysteine 74 in the GABA transporter, GAT1, and its importance in ion binding and permeation. FEBS Lett. 426, 174-178

Received 8 February 2011/28 November 2011; accepted 1 December 2011

Published as BJ Immediate Publication 1 December 2011, doi:10.1042/BJ20110247
41 Akabas, M. H., Stauffer, D. A., Xu, M. and Karlin, A. (1992) Acetylcholine receptor channel structure probed in cysteine-substitution mutants. Science $\mathbf{2 5 8}, 307-310$

42 Broer, A., Balkrishna, S., Kottra, G., Davis, S., Oakley, A. and Broer, S. (2009) Sodium translocation by the iminoglycinuria associated imino transporter (SLC6A20). Mol. Membr. Biol. 26, 333-346

43 Field, J. R., Henry, L. K. and Blakely, R. D. (2010) Transmembrane domain 6 of the human serotonin transporter contributes to an aqueously accessible binding pocket for serotonin and the psychostimulant 3,4-methylene dioxymethamphetamine. J. Biol. Chem. $\mathbf{2 8 5}$ $11270-11280$

44 Henry, L. K., Iwamoto, H., Field, J. R., Kaufmann, K., Dawson, E. S., Jacobs, M. T., Adams, C., Felts, B., Zdravkovic, I., Armstrong, V. et al. (2011) A conserved asparagine residue in transmembrane segment 1 (TM1) of serotonin transporter dictates chloride-coupled neurotransmitter transport. J. Biol. Chem. 286, 30823-30836

45 Quick, M., L00, D. D. and Wright, E. M. (2001) Neutralization of a conserved amino acid residue in the human $\mathrm{Na}^{+}$/glucose transporter (hSGLT1) generates a glucose-gated $\mathrm{H}^{+}$ channel. J. Biol. Chem. 276, 1728-1734

$46 \mathrm{Ni}$, Y. G., Chen, J. G., Androutsellis-Theotokis, A., Huang, C. J., Moczydlowski, E. and Rudnick, G. (2001) A lithium-induced conformational change in serotonin transporter alters cocaine binding, ion conductance, and reactivity of Cys-109. J. Biol. Chem. 276 30942-30947

47 Silverman, R. B. (1992) The Organic Chemistry of Drug Design and Drug Action, Academic Press, San Diego

48 Larsson, H. P., Wang, X., Lev, B., Baconguis, I., Caplan, D. A., Vyleta, N. P., Koch, H. P. Diez-Sampedro, A. and Noskov, S. Y. (2010) Evidence for a third sodium-binding site in glutamate transporters suggests an ion/substrate coupling model. Proc. Natl. Acad. Sci. U.S.A. 107, 13912-13917

49 Caplan, D. A., Subbotina, J. O. and Noskov, S. Y. (2008) Molecular mechanism of ion-ion and ion-substrate coupling in the $\mathrm{Na}^{+}$-dependent leucine transporter LeuT. Biophys. J. 95. $4613-4621$ 


\section{SUPPLEMENTARY ONLINE DATA}

\section{An aspartate residue in the external vestibule of GLYT2 (glycine transporter 2) controls cation access and transport coupling}

Gonzalo PÉREZ-SILES* $\dagger$, Enrique NÚÑEZ ${ }^{\star} \dagger+$, Antonio MORREALE*, Esperanza JIMÉNEZ* †t, Alejandra LEO-MACÍAS*, Guillermo PITA*, Francesca CHERUBINO§\|, Rachele SANGALETTI§, Elena BOSSI§§, Ángel R. ORTÍZ*1, Carmen ARAGÓN* $+\ddagger$ and Beatriz LÓPEZ-CORCUERA* $+\ddagger^{2}$

*Departamento de Biología Molecular, Centro de Biología Molecular 'Severo Ochoa' (CSIC-UAM), Universidad Autónoma de Madrid, 28049 Madrid, Spain, †Centro de Investigación Biomédica en Red de Enfermedades Raras (CIBERER), ISCIII, 28029 Madrid, Spain, †IDIPAZ-Hospital Universitario La Paz, Universidad Autónoma de Madrid, 28049 Madrid, Spain, $\S$ Laboratory of Cellular and Molecular Physiology, Department of Structural and Functional Biology and Centre for Neuroscience, University of Insubria, 21100 Varese, Italy, and „|Fondazione Maugeri IRCCS, Via Roncaccio 16, 21049 Tradate (VA), Italy

See the following pages for Supplementary Figures S1 and S2. 
GLYT2a WRFPYLAEC

GLYT2a WRFPYLAFQNGGGA

GLYT1b WRFPYLCYRNGGGA

PROT WRFPYRAYTNGGGA

IMINO WRFPYLCQMYGGGS

$\mathrm{ATB}^{0+}$ WRFPYLTYTNGGGA

$\mathrm{B}^{\mathbf{0}} \mathrm{AT} 1$ WRFPYLCQSHGGGA

TAUT WRFPYLCYKNGGGA

GAT1 WRFPYLCGKNGGGA

GAT2 WRFPYLCYKNGGGA

GAT3 WRFPYLCYKNGGGA

BGT1 WRFPYLCYKNGGGA

CREAT WRFPYLCYKNGGGV

DAT WRFPYLCYKNGGGA

NET WRFPYLCYKNGGGA

SERT WRFPYICYQNGGGA

LeuTA LRFPVQAAENGGGA

$\prod_{\text {IAMLIISVLIAIYYNVIICYTLFYL }}^{288}$ YGMMVVSTYIGIYYNVVICIAFYYF AAMLLIVGLVAIYYNMI IAYVLFYL VASVVVSFFLSMYYNVINAWGFWYL ITMVLISIFVTIYYNVI IAYSLYYL IASMFVSFMVGLYYNTI IAWVMWYF YASIVIVSLLNVYYIVILAWATYYL LAAAVLSFWLNIYYIVI ISWAIYYL YASQMIVSLLNVYYIVVLAWALFYL YATQVIEAHLNVYYIIILAWAIFYL MASVVIESYLNIYYIIILAWALFYL YASMVIVFYCNTYYIMVLAWGFYYL FTVILISFYVGFFYNVI IAWALHYF YAVILIALYVGFYYNVIIAWSLYYL YAICI IAFYIASYYNTIIAWALYYL VFGLWIPLVVAIYYVYIESWTLGFA

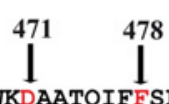

GLYT2a WEKLTDATVWKDAATQIFFSLSAAWGGLITLSSY GLYT1b WDKILEAKVWGDAASQIFYSLGCAWGGLITMASY PROT FHHLLSSKVWIEAALQIFYSLGVGFGGLLTFASY IMINO IEQLANPKAWINAATQIFFSLGLGFGSLIAFASY $\mathrm{ATB}^{0+}$ FTKLREAEVWKDAATQIFYSLSVAWGGLVALSSY $\mathrm{B}^{0} \mathrm{AT} 1$ ITELSNPNTWLDAGAQVFYSFSLAFGGLISFSSY TAUT ISRLEDPQVWIDAGTQIFFSYAICLGAMTSLGSY GAT1 FRKLSDSEVWLDAATQIFFSYGLGLGSLIALGSY GAT2 ITRLWDPQVWMDAGTQIFFSFAICLGCLTALGSY

GAT3 LSRLSDPQVWVDAGTQIFFSYAICLGCLTALGSY BGT1 LLRLKDPQVWMDAGTQIFFSFAICQGCLTALGSY CREAT WSKLGSPQVWIDAGTQIFFSYAIGLGALTALGSY DAT FYRLCEASVWIDAATQVCFSLGVGFGVLIAFSSY NET FYRLKEATVWIDAATQIFFSLGAGFGVLIAFASY SERT WOKLLETGVWVDAAAQIFFSLGPGFGVLLAFASY LeUTA FEKLKDPGVWIAAVGQIFFTLSLGFGAIITYASY

\begin{tabular}{|c|c|c|}
\hline & 542 & 635 \\
\hline GLYT2a & --RKVNIENVADQ-- & GIYMFQLVDTYAA-SYALV \\
\hline GLYT1b & --LGVDVSRVADH-- & GIYWLLLMDNYAA-SFSLV \\
\hline PROT & --LGVPVDQVAKA-- & GMYWLVLLDDYSA-SFGLM \\
\hline IMINO & FLTASNLEEVKDYLA & GNYWFDIFNDYAA-TLSLL \\
\hline $\mathbf{A T B}^{0+}$ & --SGKEVSQVVKS-- & GIYWVHLIDHFCA-GWGIL \\
\hline $\mathbf{B}^{0} \mathrm{AT} 1$ & NVTAENFEAYQHWCN & GQYWLSLLDSYAG-SIPLL \\
\hline TAUT & --QGVDIADVAES-- & GMYVFQLFDYYAASGVCLL \\
\hline GAT1 & --TKRSIADVAAS-- & GIYVFKLFDYYSASGMSLL \\
\hline GAT2 & --QGVPISEVAES-- & GMYVFQLFDYYAASGMCLL \\
\hline GAT3 & --QGVPIAEVAES-- & GMYIFQLFD SYAASGMCLL \\
\hline BGT1 & --QGVPISEVAES-- & GMYIFQLFDYYASSGICLL \\
\hline CREAT & --QGVHISKVAES-- & GMYVFQLFDYYSASGTTLL \\
\hline DAT & --HNVPIRDVATD-- & GIYVFTLLDHFAA-GTSIL \\
\hline NET & --HKVKIEDVATE-- & GIYVLTLLDTFAA-GTSIL \\
\hline SERT & --RNEDVSEVAKDA- & GAYVVTLLEEYAT-GPAVL \\
\hline LeuTA & ---AVAIAKAGAFN- & S---LDEMDFWAG-TIGVV \\
\hline
\end{tabular}

Figure S1 Sequence alignment of the regions including the residues studied within related rat SLC6 transporters and LeuT $_{A a}$

Sequence similarity with rat GLYT2a of the regions containing Tyr221 (TM1), Tyr 288 (TM3), $\mathrm{Asp}^{471}, \mathrm{Ph}^{478}$ (TM6), Asp ${ }^{635}$ (TM10) and Asp ${ }^{542}$ [EL4 (extracellular loop 4)] from the indicated members of the SLC6 family. Residues relevant to the present study are indicated with arrows. Identical residues in the relevant positions are shown in red. 
A

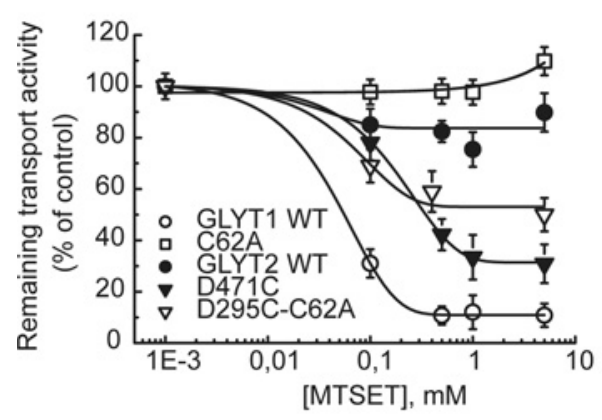

B

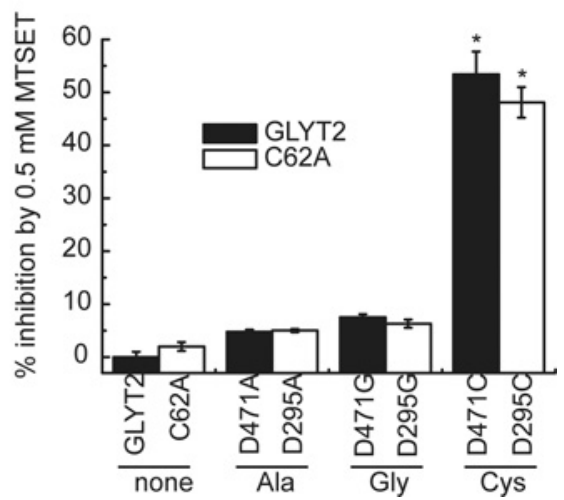

Figure S2 External accessibility of cysteine residues introduced at positions 471 (GLYT2) and 295 (GLYT1)

COS7 cells expressing the indicated transporters were treated at $22^{\circ} \mathrm{C}$ with the specified MTSET concentrations in choline chloride in HBS, then washed, and glycine transport was determined in $\mathrm{NaCl}$ HBS. (A) Experimental data were fitted to a first-order exponential decay curve. $100 \%$ glycine transport was in nmol of glycine/mg of protein per 10 min: (A) $5.0 \pm 0.5,4.3 \pm 0.2,3.2 \pm 0.2$, $0.71 \pm 0.3,0.62 \pm 0.1$ for wtGLYT1, C62A, wtGLYT2, D471A and D295A/C62A respectively and (B) $3.0 \pm 0.3,4.5 \pm 0.1,0.75 \pm 0.3,0.64 \pm 0.2,0.70 \pm 0.1,0.59 \pm 0.1,0.68 \pm 0.2,0.60 \pm 0.2$ for wtGLYT2, C62A, D471A, D295A/C62A, D471G, D295G./C62A, D471C and D295C/C62A respectively. MTSET inhibition is expressed as the fraction of uptake inhibited [100 - (100×uptake after/uptake before)]. ${ }^{*} P<0.05$ relative to background transporter (ANOVA with Dunnett's post-hoc test).

Received 8 February 2011/28 November 2011; accepted 1 December 2011

Published as BJ Immediate Publication 1 December 2011, doi:10.1042/BJ20110247 